\title{
General Marxism by Production Dimension Model, Production Evolution, and Individualism-Collectivism Duality
}

\author{
Dingyu Chung \\ Utica, MI, USA \\ Email: dy_chung@yahoo.com
}

How to cite this paper: Chung, D. Y. (2020). General Marxism by Production Dimension Model, Production Evolution, and Individualism-Collectivism Duality. Open Journal of Social Sciences, 8, 282-336. https://doi.org/10.4236/jss.2020.86025

Received: April 25, 2020

Accepted: June 14, 2020

Published: June 17, 2020

Copyright (๑) 2020 by author(s) and Scientific Research Publishing Inc. This work is licensed under the Creative Commons Attribution International License (CC BY 4.0).

http://creativecommons.org/licenses/by/4.0/

\section{(c) (i) Open Access}

\begin{abstract}
In this paper, classical Marxism as special Marxism for the mid-nineteenth century is broadened and updated into general Marxism for the twenty-first century. General Marxism includes the $5 \mathrm{~W} 1 \mathrm{H}$ production analysis for all aspects of production and the individualism-collectivism duality for the individualistic Western civilization originated from the Middle East and Greece and the collectivistic Eastern civilization originated from India and China. The $5 \mathrm{~W} 1 \mathrm{H}$ production analysis consists of when (stages) to produce for the production evolution and what (types), how much (energies), why (purposes), who (people), and where (places) to produce for the production dimension model based on the Hofstede cultural dimension model. In the statistical analysis, the indexes in the production dimension model derived from the indexes in the Hofstede model correlate well with the observed Democracy In$\operatorname{dex}(\mathrm{R} 2=0.4)$ and the GDP Growth Rate $(\mathrm{R} 2=0.8)$. The production evolution has the interdependent individualism-collectivism at the beginning (hunter-gatherer) and the end (eusocial democracy) and the split individualism-collectivism in between (pastoral-agrarian and West-East). The first five stages of the production evolution match the five modes in special Marxism. In the twentieth century, class conflict in the mid-nineteenth century (Marx's time) turned into class mobility in the true democratic governments (individualistic individual liberal democracy for individual liberty in the West and collectivistic common professional democracy for common wellbeing in the East) working for all people. In the twenty-first century, through increasing globalization in trade and investment, the individualistic West depends on the collectivistic East for consolidative production type from low-profit development, supply chain, economy of scale, and ration, while the East depends on the West for adventurous production type from high-profit invention, productivity, efficiency, and marketing. The result is the interdependent indivi-
\end{abstract}


dualism-collectivism to bring about eusocial democracy based on interdependent division of labor between individual liberal democracy and common professional democracy in the stable interconnected world.

\section{Keywords}

Marxism, Production, Production Dimension Model, Production Evolution, Hofstede Cultural Dimension Model, Individualism, Collectivism, Statistical Analysis, Eusocial Democracy

\section{Introduction}

Civilization comes from the Latin word civis which means someone who lives in a town. A civilization is a complex human society, usually made up of different cities, with certain characteristics of cultural and technological development. The earliest civilizations developed between 4000 and 3000 BCE, when the rise of agriculture and trade allowed people to have surplus food. The four major early civilizations are Lower Mesopotamia civilization between Tigris and Euphrates Rivers (3000 BCE), Egyptian civilization along the Nile River (3000 BCE), the Harappan civilization in the Indus River Valley (in present-day India and Pakistan; 2500 BCE), and Chinese civilization along the Yellow and Yangtze Rivers (2200 BCE).

The pre-civilized society is a subsistence society without material accumulation, and civilized society is a surplus society with material accumulation. The civilized human society has been the most productive society on earth, so the most important aspect of human civilization is production combining various material inputs and immaterial inputs (plans, know-how) in order to make something for consumption (output). In the production analysis by Karl Marx (Marx, 1990), the five modes of production as the stages of the production evolution are the combinations of the production forces and the production relations for the relations among the production people and places. The five modes (stages) of production based on dialectic progress are tribal band as primitive communism mode, slavery mode ruled by patricians over plebeians, feudalism mode ruled by aristocrats over bourgeoisies, capitalism mode ruled by capitalists (bourgeoisies) over proletariats, and communism mode ruled by proletariats without class conflict. Marxism is a method of production analysis that views class relations and social conflict using a dialectical interpretation of production evolution. The core of Marxism is that the emancipation of the working class (proletariats) over capitalists by revolution is inevitable through the dialectical view of the production evolution.

Even though according to Jonathan Sperber in "Karl Marx: A Nineteenth-Century Life” (Sperber, 2013), Marx wrote in the mid-nineteenth century, some Marx’s ideas are still useful in the twenty-first century according to John B. Judis (Judis, 2014). The production analysis and the production revolution are still useful. 
Marx not only helped provide us with a developmental view of history, but also helped us imagine the ways in which history moved through different stages as production modes. These transitions among production modes entailed not just a change in rule, but in how goods are produced and distributed.

The economic crisis in 2008 has spawned a resurgence of interest in Karl Marx (Panitch, 2009). The economic crisis in 2008 fulfilled the predicted crisis by Marx. He understood that the need for a constantly expanding market for its products chases the capitalists over the whole surface of the globe, foreseeing that the development of capitalism would inevitably be paving the way for more extensive and exhaustive crises. Marx identified how disastrous speculation could trigger and exacerbate crises in the whole economy.

Therefore, the resurgent Marxism in the West leads to broaden and update classical Marxism written in the mid-nineteenth century. In this way, classical Marxism becomes "special Marxism" for the mid-nineteenth century, while the broadened and updated Marxism becomes "general Marxism" for the twenty-first century. Basically, in general Marxism, the production analysis and the production evolution are broadened and updated. In this paper, general Marxism includes the mental origin of production (Chung, 2018a), the $5 \mathrm{~W} 1 \mathrm{H}$ production analysis (when, what, how, why, who, and where to produce) for all aspects of production, human biological evolution (Chung, 2018c), and the individualism-collectivism duality for the individualistic Western civilization originated from the Middle East and Greece and the collectivistic Eastern civilization originated from India and China (Chung, 2020).

The $5 \mathrm{~W} 1 \mathrm{H}$ production analysis consists of the production dimension model based on the Hofstede cultural dimension model (Hofstede et al., 2010) and the production evolution. The indexes in the production dimension model are derived from the indexes from the Hofstede model. In the statistical analysis as shown in this paper, the indexes from the production dimension model correlate well with the observed Democracy Index $(\mathrm{R} 2=0.4)$ and the GDP Growth Rate $(\mathrm{R} 2=0.8)$.

The production evolution has the interdependent individualism-collectivism at the beginning (hunter-gatherer) and the end (eusocial democracy) and the split individualism-collectivism in between (pastoral-agrarian and West-East). The first five stages of the production evolution match the five modes in special Marxism. The first five modes (stages) are the linked band stage by the Upper Paleolithic Revolution, the split tribe stage (collective-individualistic territorial tribalism) by the Agricultural-Pastoral Revolution, the split nation stage (authoritarianism-feudalism) by the Bronze Revolution, the split mega nation stage (meritocracy-capitalism) by the Iron Revolution, and the split democracy stage (individual liberal democracy-common professional democracy) by the Industrial Revolution corresponding to the primitive communism, slave state, feudalism, capitalism, and communism modes, respectively in special Marxism.

In the twentieth century, class conflict in the elite governments working for 
the elite in the mid-nineteenth century (Marx's time) turned into class mobility in the true democratic governments (individualistic individual liberal democracy in the West and collectivistic common professional democracy in the East) working for all people. In the twenty-first century, through increasing globalization in trade and investment, the individualistic West depends on the collectivistic East for the collectivistic production type from low-profit development, supply chain, economy of scale, and ration, while the East depends on the West for the individualistic production type from high-profit invention, productivity, efficiency, and marketing. The result is the interdependent individualism-collectivism for "eusocial democracy" (Crespi \& Douglas, 1995) based on interdependent division of labor between individualistic individual liberal democracy and collectivistic common professional democracy in the stable interconnected world.

Section 2 describes the mental origin of production. Section 3 explains the Hofstede Cultural Dimension Model and the Production Dimension Model. Section 4 describes the production evolution.

\section{The Mental Origin of Production}

The mental origin of production explains all mental capacities to develop civilized production. The paper proposes that the mental origin of production consists of the social brain for instinctive intragroup relations and worldviews to form the original small human production group, the mental immune system for instinctive mental therapy, theory of imaginary mind for imaginary religious and political entities with their own minds to form cohesive large production group, and the thinking brain for rational rule to form rational civilization.

\subsection{The Social Brain}

The social brain (Dunbar, 2009; Dunbar, 2016; Frith, 2007; Cozolino, 2006) is the network of brain regions that are involved in understanding others. We are biologically hard-wired for interacting with others. The social brain is located mainly in the neocortex in the outmost layer of the brain. The neocortex is much larger in humans as compared to other primates and mammals of similar size. The social brain also involves the neurotransmitter/hormone system to provide a psychopharmacological platform for the cognitive component.

The social brain contains instinctive relations to form the default social structure. All social animals have instinctive relations to form the default social structures without training or with little training. The human social brain consists of instinctive intragroup relations and instinctive worldviews. The social brain for instinctive intragroup relations and worldviews is to form the original small human production group.

\subsubsection{The Intragroup Relations}

In the human social brain, intragroup relations consist of family, alliance, division of labor, and multigenerational relations The four intragroup relations to 
protect social members are family intragroup relation to protect vulnerable children through commitment, alliance intragroup relation to protect vulnerable individuals through reciprocity, division of labor intragroup relation from interdependent specialists to protect vulnerable pregnant females through interdependence, and multigenerational intragroup relation from older leaders-mentors to protect next generation through generativity (legacy).

Family intragroup relation benefits vulnerable children against neglect by forming kinship group (Hamilton, 1964) whose relations depend on commitment to a social group rather than reciprocal benefit of individuals. The origin of collectivistic intragroup relation is the social group of caregivers and vulnerable children. For non-primate vertebrates, the brain size for family intragroup relation is proportional to the duration and complexity of commitment (Shultz \& Dunbar, 2007). The neurotransmitter to promote family intragroup relation is oxytocin, so people feel good when they are with their kin.

Alliance intragroup relation benefits vulnerable individuals against predation by forming an alliance group (Cozolino, 2006) whose relations depend on reciprocal benefit of individuals rather than commitment to a social group. The base of alliance intragroup relation is extensive and complex socialization. For primates, the brain size for alliance intragroup relation is proportional to the group size and the complexity of socialization. According to Dunbar, the proper group size based on the human brain size is around 150 (Dunbar, 1993). The neurotransmitter to promote alliance intragroup relation is endorphins, so people feel good when they have friends.

Division of labor intragroup relation benefits vulnerable specialists against handicaps by forming a specialist group from specialists whose relations depend on existential interdependence (Wilson, 2012; Chung, 2016). The early hominins formed the interdependent specialist groups consisting of the forest group of homemaker-forager for women and children and the woodland group of adventurist-forager for men in the mixed forest-woodland habitat. The handicap was the feet which were still suitable for climbing trees, and not suitable to walk long distance and run fast on the ground especially for pregnant women and small children in woodland area. Later, the division of labor became gatherer-hunter in open savanna habitat. This division of labor intragroup relation is called eusociality (Crespi \& Douglas, 1995) characterized by the division of labor. Eusociality is the highest level of organization of animal sociality in certain insects, crustaceans, and mammals. Ants, bees, and termites are eusocial animals. Homo sapiens are also eusocial (Wilson, 2012). Division of labor requires mind-reading mentalization derived from theory of mind (Fonagy et al., 2002).

Multigenerational intragroup relation benefits future generations by forming multigenerational group whose relations depend on generativity (Erikson \& Erikson, 1998; Slater, 2003; McAdams \& De St. Aubin, 1992; Chung, 2018b). Unlike great apes, infertile women have long life after menopause allows multiple generations to live together. The caring of infertile women after menopause for their grandchildren and great-grandchildren is the base of legacy. Therefore, 
the four intragroup relations are family intragroup relation to benefit vulnerable children through commitment, alliance intragroup relation from allies to benefit vulnerable individuals through reciprocity, division of labor intragroup relation from specialists to benefit vulnerable specialists through interdependence, and multigenerational intragroup relation from multiple generations to benefit vulnerable future generations through generativity. These instinctive intragroup relations produce the default social structure with family group, alliance group, division of labor, and generational assistance.

\subsubsection{Worldviews}

For social animals, instinctive worldview (intergroup relation) is derived from ingroup and outgroup. In ingroup, individuals share similar interests and attitudes, and produce instinctive feeling of ingroup favoritism as solidarity, community, and exclusivity (Turner \& Reynolds, 2010). Individuals in outgroup outside one's own group are different in interests and attitudes, and produce instinctive feeling of outgroup derogation as inferiority and alienation. Morality is defined as proper behavior. Morality toward ingroup is opposite of morality toward outgroup (Cohen, Montoya, \& Insko, 2006). Ingroup morality is cooperative connection derived from instinctive ingroup favoritism. Outgroup morality is zero-sum aggressive competition derived from mutual outgroup derogation among social groups. According to evolutionary psychologists, this discrimination between collectivistic ingroup morality and competitive outgroup morality has evolved because it enhances group survival in terms of instinctive cooperative connection toward ingroup and instinctive aggressive competition toward outgroup (Shultz, Hartshorn, \& Kaznatcheev, 2009).

Such attitudes toward ingroup and outgroup are instinctive, appearing even in babies at few months old. As shown in the Infant Cognition Center at Yale University (Hamlin, Mahajan, \& Wynn, 2013), babies prefer the objects (such as dolls) as ingroup objects that have similarities with the babies rather than the objects as outgroup objects that do not have similarities with the babies. Babies also prefer the objects with helpful behavior to the objects with bully behavior. However, babies prefer the doll that bullies another doll that is not like the babies. In other words, even though babies dislike the individuals who harm other individuals, babies prefer the individuals who harm outgroup individuals that are not like the babies. The zero-sum competitive attitude toward outgroup is instinctive. On the basic level, the relation toward outgroup is individualistic without connection, while the relation toward ingroup is collectivistic with connection.

This bimodal ingroup and outgroup relate to the bimodal proactive aggression and reactive aggression, respectively (Wrangham, 2018). Proactive aggression generally results from the conflict toward outgroup, while reactive aggression generally comes from the conflict toward ingroup (Nesdale \& Duffy, 2011). The distinction between the two types is centered on the aims of aggression. Proactive aggression aiming at outgroup involves a purposeful planned attack with an 
external or internal reward as a goal. It is characterized by attention to a consistent target, and often by a lack of emotional arousal. By contrast, reactive aggression aiming at ingroup is a response to a threat or frustrating event, with the goal being only to remove the provoking stimulus. Proactive aggression toward outgroup is characterized by low physiological arousal, a lack of social communication, and targeting of vulnerable body parts, because outgroup is basically an individualistic group without any connection to the aggressor. By contrast, reactive aggression toward ingroup is associated with high physiological arousal and communication of intent including threats, because ingroup is basically a collectivistic group with connection with the aggressor. The two types are sometimes easy to distinguish. For example, when two animals compete with steadily escalating intensity, as frequently occurs in fights over food or mates, aggression is typically reactive without any proactive elements.

Tulogdi et al. (Tulogdi et al., 2010) found that proactive aggression was associated with innervation of the central and basolateral amygdala, the lateral hypothalamus, and the ventrolateral periaqueductal gray. By contrast, reactive aggression was associated with the medial amygdala, the mediobasal hypothalamus, and the dorsal periaqueductal gray (Tulogdi et al., 2015). The results of Tulogdi et al. indicate the existence of two different pathways in a key neural circuit underlying aggression.

Humans were evolved with territorial worldview with rigid boundary to separate ingroup and outgroup. On the other hand, chimpanzee and bonobo have fission-fusion society with overlapping social groups in which the social group size and composition change throughout the year with different activities and situations. As a result they do not have rigid boundary between ingroup and outgroup. The natural habitats of chimpanzees and bonobos are separated by Congo River. The poor natural habitat where chimpanzees live has much higher resource competition than the rich natural habitat where bonobos live. Therefore, the core worldview of chimpanzees is individualism worldview adaptive to competition, while the core worldview of bonobos is collectivism worldview adaptive to cooperation. Individualism worldview in chimpanzee is shown in a high propensity for proactive aggression and reactive aggression, while collectivism worldview in bonobo is shown in a low propensity for proactive aggression and reactive aggression. Compared with chimpanzees and bonobos, humans have a high propensity for proactive aggression like chimpanzees and unlike bonobos, and a low propensity for reactive aggression unlike chimpanzees and like bonobos (Wrangham, 2018). In bonobos, no proactive aggression leading to intergroup killings has been observed (Wilson et al., 2014). Proactive aggression toward conspecifics is accordingly much more common in chimpanzees and humans than in bonobos, where it is infrequent or absent. The highly aggressive behaviors of adult male chimpanzees can be described as male warriors (McDonald et al., 2012). Because of division of labor intragroup relation based on interdependence in humans, chimpanzees and bonobos without division of labor intragroup relation both show higher reactive aggression toward ingroup than 
humans. The human low propensity for reactive aggression toward ingroup is shown in human small canine teeth unlike large canine teeth in other animals for ingroup fighting. The two important traits that distinguish early hominins from other apes are bipedalism and small canine teeth. The worldviews of human, chimpanzee, and bonobo are in Table 1.

Therefore, the evolution of the worldviews and human-bonobo-chimpanzee started with their common ancestors with territorialism and unseparated labor. With bipedalism as mention in the previous subsection, human was split from the common ancestors to establish division of labor with territorialism. With flexible boundary, bonobo and chimpanzee were split into collectivistic bonobo and individualistic chimpanzee as in Figure 1.

\subsection{The Mental Immune System}

The immune system is a network of cells, tissues, and organs that work together to provide countermeasures against harmful invaders (pathogens). Different immune subsystems provide different countermeasures against different harmful invaders. The balanced immune system has the immune system regulators to balance the activities of the immune system. As the highly imbalanced immune system without the proper immune system regulators, the overactive immune system causes allergies and auto immune diseases as physical disorders against ubiquitous harmful and harmless detected invaders.

In the same way, in the mental immune system, the different mental immune subsystems provide the different countermeasures against different adversities

Table 1. Worldviews.

\begin{tabular}{cccccc}
\hline Worldview & Boundary & Intergroup & $\begin{array}{c}\text { Proactive } \\
\text { aggression }\end{array}$ & $\begin{array}{c}\text { Reactive } \\
\text { aggression }\end{array}$ & Example \\
\hline Territorialism & rigid & ingroup-outgroup & High & lowest & human \\
Individualism & flexible & extended outgroup & High & high & chimpanzee \\
Collectivism & flexible & extended ingroup & Low & low & bonobo \\
\hline
\end{tabular}

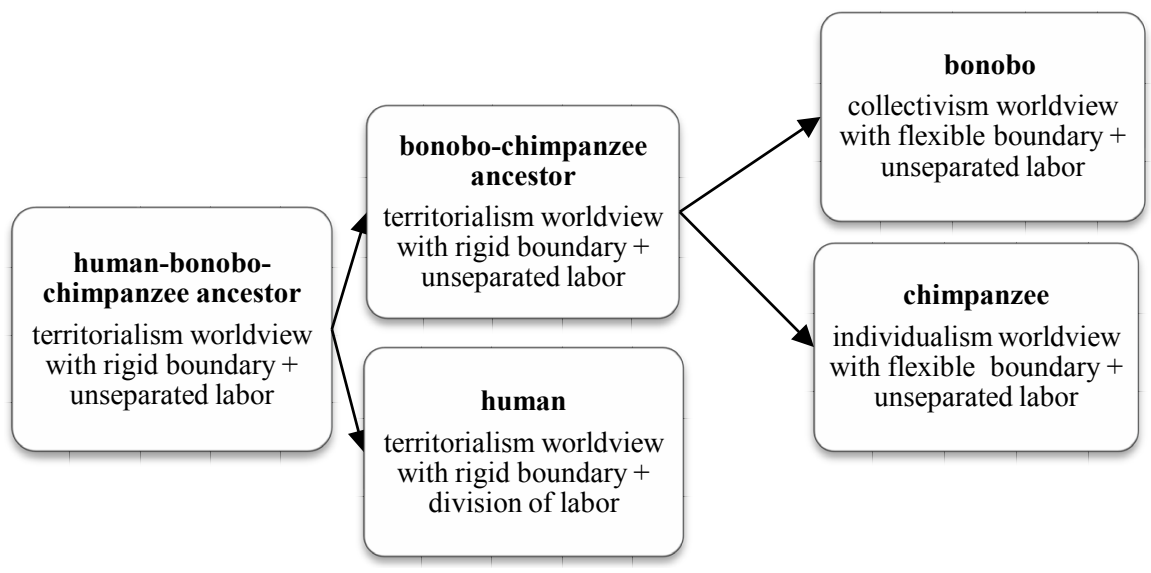

Figure 1. The developments of territorialism, collectivism, and individualism. 
(Chung, 2018a). The balanced mental immune system has the mental immune system regulators to balance the activities of the mental immune system. As the highly imbalanced mental immune system without the proper mental immune system regulators, the overactive mental immune system causes mental allergies and auto immune diseases as personality-mental disorders (American Psychiatric Association, 2013) against ubiquitous harmful and harmless perceived adversities.

The instinctive mental countermeasures in the mental immune system include comforter against hardship, hyperactivity against danger, and phobia against unfamiliarity-uncertainty. Each countermeasure has its regulator to avoid excess countermeasure. The excessive countermeasure without balancing by the regulator leads to the personality disorder. The mental immune system is instinctive, because it is mediated by neurotransmitters.

\subsection{Theory of Imaginary Mind}

All supernatural entities and large social groups entities such as nation-states are derived from theory of imaginary mind where a person attribute mental states of mind (beliefs, intents, desires, emotions, knowledge, etc.) to imaginary others (supernatural deities and nation-states), and understand that imaginary others have beliefs, desires, intentions, and perspectives that are different from the person. Theory of imaginary mind is derived from theory of real mind as the original theory of mind a person attribute mental state of mind to the others as real people, not imaginary entities. No other animals have such robust theory of mind, so other animals do not have religions and nation-states. As shown in the previous paper (Chung, 2018c), theory of mind was not evolved originally to accommodate religious behaviors. Theory of mind was evolved originally to accommodate interdependent division of labor between the forest specialist group (women and children) and the woodland specialist group (men) in early hominins who lived the mixed forest-woodland habitat. To complement each other's work without interfering each other's work, one specialist group had to recognize that the other specialist group existed to think for themselves and to do different works. The result was theory of mind which is to recognize that the others exist to think for themselves. (The forest-woodland groups became the hunter-gatherer groups for the Homo species in the savanna habitat.) Under normal condition, specialists in division of labor were real.

Humans under existential pressure invented theory of imaginary mind for imaginary specialists as imaginary agents who existed to think for themselves and to do different work in imaginary division of labor to enhance survival chance, resulting in the religious relief of stress and anxiety to enhance the survival chance of individuals. Under existential pressure, such theistic imagination can also be the religious enforcement of social bonds to enhance the survival chance of social group (Norenzayan et al., 2016; Shilling \& Mellor, 1998). Robust religion is unique to humans, because robust theory of mind is unique to hu- 
mans (Heyes, 2015). According to Maurice Bloch (Bloch, 2006), the first widespread human religion was derived from the imagination to produce imaginary female figurines and imaginary cave paintings to helps them to survive under existential pressure at the time of the Upper Paleolithic Revolution.

According to a PET study, theory of mind activates the medial prefrontal node to handle the mental state of the self, the superior temporal sulcus to detect the behavior of other animals and analyzes the goals and outcomes of this behavior, and the inferior frontal region to maintain representations of actions and goals (Calarge, Andreasen, \& O'Leary, 2003). According to Kapogiannis and Deshpande in the functional MRI study of the brains of both self-declared religious and non-religious individuals, individuals with stronger theory of mind activity were found to be more religious (Kapogiannis et al., 2014). Thinking about God activates brain regions associated with theory of mind (Kapogiannis et al., 2009). Autistic individuals with problems in imaginative capacities and pretend plays are incapable of theory of mind (Scott \& Baron-Cohen, 1996; Angus et al., 2015; Chan et al., 2016). Autism with the deficits in theory of mind is linked to lower belief in God (Norenzayan, Gervais, \& Trzesniewski, 2012).

Up to two-thirds of the children who have the ability for theory of mind between the ages of 3 and 8 have imaginary companions (Taylor, 1999). They need imaginary companions to provide comfort in times of stress, boredom, and loneliness, to help them make sense of the adult world, and to overcome traumatic experiences. Taylor feel imaginary companions are common among children and are part of normal social-cognitive development (Taylor et al., 2004). For adults, such childhood imaginary companions are replaced by adulthood imaginary guardians who intertwine closely with the real social brain and the real mental immune system. As a result, to believers, such imaginary guardians become real supernatural guardians to maintain cohesive large social group and to uphold believers' mental health. Large social groups and believers cannot survive well without adulthood imaginary guardians.

\subsection{The Thinking Brain}

The brain includes the emotional-instinctive brain, the subjective thinking brain, and the objective thinking brain (Westen, 2008). The emotional-instinctive brain locates in the subcortex and the limbic regions, and the neurotransmitters include endorphins for individualistic intragroup relation and oxytocin for collectivistic intragroup relation. Emotion and instinct are blunt and black-and-white reactions without discerning. They occur extremely rapidly before conscious thoughts. The subjective thinking brain uses reasoning to defend the view derived from instinct and emotion against the opposite point of view. The subjective thinking brain locates in the orbital frontal cortex for the processing of emotions, the anterior cingulate for conflict resolution, the posterior cingulate for making judgments about moral accountability, and the ventral striatum for reward and pleasure. The neurotransmitters are glutamine and dopamine. The 
objective thinking brain locates in the dorsolateral prefrontal cortex for objective reasoning and analysis without bias. The neurotransmitter is glutamine. Objective thinking plays a limited role in decisions. According to Drew Westen, only between 0.5 and 3 percent of the most important political decisions utilize objective thinking. For rational civilization, the thinking brain formulas the rational rules to control both proactive aggression and reactive aggression.

\section{The Hofstede Cultural Dimension Model and the Production Dimension Model}

The Hofstede's six cultural dimensions (Hofstede et al., 2010) include individualism versus collectivism (IDV), power distance index (PDI), masculinity versus femininity (MAS), uncertainty avoidance index (UAI), long term orientation versus short term normative orientation (LTO), and indulgence versus restraint (IVR) to represent differences among national cultures, and each dimension in each national culture is given a numerical index from survey of people in different nations as publish in "Cultures and Organizations: Software of the Mind” (2010)" (Hofstede et al., 2010). The Production Dimension Model based on the Hofstede Cultural Dimension Model has three production force dimensions, consisting of the production types, the production energies, and the production purposes.

\subsection{Production Types}

The production types (adventurous-consolidative types) from the Production Dimension Model are derived from Individualism versus collectivism (IDV) and power distance index (PDI) from the Cultural Dimension Model. Based on high side of individualism versus collectivism (IDV), individualism can be defined as a preference for a loosely-knit social framework in which individuals are expected to take care of only themselves and their immediate families. Its opposite, collectivism, represents a preference for a tightly-knit framework in society in which individuals can expect their relatives or members of a particular ingroup to look after them in exchange for unquestioning loyalty. A society's position on this dimension is reflected in whether people's self-image is defined in terms of "I" or "we." The IDV index increases with increased individualism.

The mental origin of individualism is extended outgroup where every adult is considered equally as outgroup without ingroup relations such as commitment and reciprocity, so everyone is an independent individual without ingroup relation. The mental origin of collectivism is extended ingroup where all adults are considered as ingroup with ingroup relations such as commitment and reciprocity, so all adults have ingroup relations with other adults. The original source of individualism is derived from individualistic nomadic pastoral-trade tribe on arid land, while the original source of collectivism is derived from agrarian tribe. According to R. E. Nisbett et al., most subsistence research has compared herders and farmers, arguing that the independence and mobility of herding make 
herding cultures individualistic and that the stability and high labor demands of farming make farming cultures collectivistic (Nisbett et al., 2001). The production type for nomadic pastoral-trade tribe was the adventurous type to produce high-profit, high risk, and low coordination products from frequent migration, military plundering and risky trades. The production type for agrarian tribe is consolidative type to produce high (capital and labor) consolidative, low risk, and high coordination products from consolidative irrigation and infrastructure.

Power distance index (PDI) expresses the production relation toward people in different hierarchies which are different in terms of ages, wealth, experience, education, social demand, and expertise. People in societies with high Power Distance accept and respect such hierarchical order where everybody has a place and which needs no further justification in such way that everyone is a professional in one's hierarchy. High Power Distance is basically division of professional. People in low Power Distance have liberty to challenge continuously the justification for such hierarchical order. Low Power Distance is basically liberty. The PDI index increases with increased Power Distance.

The original source of liberty (low PDI) is derived from the expansion of individualistic nations to mega nations such as mega empires during the Axial Age from Greece and the Middle East and again during the Enlightenment. The individualistic mega nations were ruled by the majority of free (liberal) elite nobilities, landowners, traders, and industrialists. The original source of division of professional (high PDI) is derived from the expansion of agrarian nations to mega nations such as mega empires from India and China during the Axial Age. The collectivistic mega empires were ruled by elite professionals.

In the production dimension model, the production types (adventurous and consolidative types) are derived from the combination of IDV and PDI. The production types are dualistic with yin and yang consisting of the consolidative type as yin and the adventurous type as yang. The adventurous type to produce high-profit, high risk, and low coordination products has the production relations of high IDV (high individualism) and low PDI (low power distance = liberty). Adventurous production type is adaptable to individual liberal democracy based on liberal individualism. The industrial adventurous production type is strong in high-profit invention, productivity, efficiency, and marketing.

Consolidative production type to produce high (capital and labor) consolidative, low risk, and high coordination products has the production relations of low IDV (high collectivism) and high PDI (high power distance $=$ division of professional). Consolidative production type is adaptable to common professional democracy based on professional collectivism. The industrial consolidative production type is strong in low-profit development, supply chain, economy of scale, and ration.

The potential type index (PTI) is as follows.

$$
\mathrm{PTI}=(\mathrm{IDV}-\mathrm{PDI}) / 2
$$

The high value of PTI represents the high propensity for individual liberal de- 
mocracy, while low value of PTI represents the high propensity for common professional democracy. As a result, PTI identifies the potential of each nation for certain type of democracy. The statistical correlation between PTI and DI (Democracy Index (The Economist Intelligence Unit, 2020)) results in the best-fit equation, the deviation between the expected DI and DI, and R2 value. The best-fit equation between PTI and DI and its R2 are shown in Equation (2).

$$
\begin{aligned}
\mathrm{DI}_{\text {exp ected }} & =0.0546 \mathrm{PTI}+7.435 \quad \mathrm{R} 2=0.4 \\
\% \text { deviation } & =100 \times\left(\mathrm{DI}_{\text {exp ected }}-\mathrm{DI}_{\text {obsered }}\right) / \mathrm{DI}_{\text {exp ected }}
\end{aligned}
$$

The correlation between PTI and DI is moderate $(\mathrm{R} 2=0.4)$. The calculated result for the countries in the Hofstede culture model is shown in Table 2.

In Table 2, the preference to individual liberal democracy increases with the increasing potential type index (PTI), while the preference to common professional democracy increases with the decreasing PTI. From the PTI (about 15 points for each group), the five groups are the potential strong individual liberal democracy, the potential adequate individual liberal democracy, the potential neutral democracy with equal preference to both democracies, the adequate common professional democracy, and the strong common professional democracy. In Table 2, Arabic-speaking countries in the Hofstede model is represented by Saudi Arabia, East Africa is represented by Tanzania, and West Africa is represented by Nigeria. In Table 2, two regions in one country in the Hofstede model are combined into one according to their respective populations.

The results of the potential democracy types show that in terms of Christian culture, Protestant Christian culture prefers mostly potential strong individual liberal democracy, Catholic Christian culture prefers mostly potential adequate individual liberal democracy, potential neutral democracy, and potential adequate common professional democracy depending on locations, and Eastern Orthodox Christian culture mostly prefers potential neutral democracy and potential adequate common professional democracy. Israel prefers potential strong individual liberal democracy. In Asia, only Japan barely prefers potential adequate individual liberal democracy because of its active westernization since 1868 (The Meiji Restoration). All other countries with Confucian culture prefer potential adequate common professional democracy. India prefers potential neutral democracy, and all other countries with Indian culture prefer mostly potential adequate common professional democracy. Only Iran and Turkey prefer potential neutral democracy, and all other countries with Muslim culture prefer mostly adequate common professional democracy.

In Table 2, the \% deviation is the deviation of actual DI from the expected DI. Within $\pm 10 \%$ deviation can be considered as normal. $>10 \%$ deviation occurs when the expected DI is $>10 \%$ greater the observed DI which means the country is expected to be more individual liberal democracy than the observed. The abnormality is shown as political restriction. Political restriction as abnormality indicates abnormal threat to the country. In Table 2, the countries with the 
Table 2. The correlation between potential type index (PTI) and observed democracy index (DI).

\begin{tabular}{|c|c|c|c|c|c|c|c|c|c|}
\hline Political unit & PTI & DI & $\%$ deviation & Abnormality & political unit & PTI & DI & $\%$ deviation & abnormality \\
\hline$\underline{++\mathrm{I}-\mathrm{L}}$ & & & & & India & -14.5 & 7.2 & $-8.1 \%$ & normal \\
\hline New Zealand & 28.5 & 9.3 & $-2.9 \%$ & normal & Turkey & -14.5 & 4.4 & $52.0 \%$ & restriction \\
\hline Denmark & 28 & 9.2 & $-2.8 \%$ & normal & Brazil & -15.5 & 7.0 & $-5.5 \%$ & normal \\
\hline Great Britain & 27 & 8.5 & $4.4 \%$ & normal & Trinidad & -15.5 & 7.2 & $-8.0 \%$ & normal \\
\hline Australia & 26 & 9.1 & $-2.6 \%$ & normal & Portugal & -18.0 & 7.8 & $-17.7 \%$ & chaos \\
\hline United States & 25.5 & 8.0 & $10.9 \%$ & restriction & Tanzania & -18.5 & 4.4 & $45.7 \%$ & restriction \\
\hline Austria & 22 & 8.3 & $4.2 \%$ & normal & Bulgaria & -19.0 & 7.0 & $-9.8 \%$ & normal \\
\hline Ireland & 21 & 9.2 & $-6.2 \%$ & normal & Croatia & -20.0 & 6.6 & $-3.5 \%$ & normal \\
\hline Netherlands & 21 & 8.9 & $-3.5 \%$ & normal & Chile & -20.0 & 8.0 & $-20.4 \%$ & chaos \\
\hline Canada & 20.5 & 9.2 & $-6.5 \%$ & normal & $\underline{\text { C-P }}$ & & & & \\
\hline Israel & 20.5 & 7.8 & $9.8 \%$ & normal & Pakistan & 29.5 & 4.2 & $51.5 \%$ & restriction \\
\hline Sweden & 20 & 9.4 & $-9.2 \%$ & normal & Taiwan (China) & 29.5 & 7.7 & $-18.3 \%$ & chaos \\
\hline Norway & 19 & 9.9 & $-14.2 \%$ & chaos & Slovenia & 29.5 & 7.5 & $-15.8 \%$ & chaos \\
\hline Hungary & 17 & 6.6 & $26.1 \%$ & restriction & S Korea & 29.0 & 8.0 & $-21.4 \%$ & chaos \\
\hline Germany & 16 & 8.7 & $-4.3 \%$ & normal & Saudi Arab & 29.0 & 1.9 & $225.8 \%$ & restriction \\
\hline Switzerland & 15.4 & 9.0 & $-8.4 \%$ & normal & Hong Kong (China) & 28.5 & 6.2 & $1.8 \%$ & normal \\
\hline Finland & 15 & 9.1 & $-9.7 \%$ & normal & Thailand & 28.0 & 4.6 & $34.6 \%$ & restriction \\
\hline Italy & 13 & 7.7 & $5.6 \%$ & normal & El Salvador & 26.5 & 6.0 & $3.2 \%$ & normal \\
\hline Latvia & 13 & 7.4 & $10.4 \%$ & restriction & Peru & 26.0 & 6.6 & $-7.2 \%$ & normal \\
\hline Estonia & 10 & 8.0 & $0.1 \%$ & normal & Vietnam & 25.0 & 3.1 & $97.1 \%$ & restriction \\
\hline Luxembourg & 10 & 8.8 & $-9.4 \%$ & normal & Mexico & 24.5 & 6.2 & $-2.4 \%$ & normal \\
\hline$\underline{\mathrm{I}-\mathrm{L}}$ & & & & & Slovakia & 24.0 & 7.1 & $-15.3 \%$ & chaos \\
\hline Lithuania & 9 & 7.5 & $5.7 \%$ & normal & Singapore & 23.0 & 6.4 & $-6.6 \%$ & normal \\
\hline S Africa & 8 & 7.2 & $8.7 \%$ & normal & Russia & 23.0 & 2.9 & $102.7 \%$ & restriction \\
\hline Belgium & 5.5 & 7.8 & $-0.6 \%$ & normal & Colombia & 23.0 & 7.0 & $-14.4 \%$ & normal \\
\hline France & 1.5 & 7.8 & $-3.6 \%$ & normal & Nigeria & 21.5 & 4.4 & $32.4 \%$ & restriction \\
\hline Malta & 1.5 & 8.2 & $-8.4 \%$ & normal & China & 20.0 & 3.3 & $74.6 \%$ & restriction \\
\hline Czech Rep. & 0.5 & 7.7 & $-3.0 \%$ & normal & Bangladesh & 20.0 & 5.6 & $4.1 \%$ & normal \\
\hline Argentina & -1.5 & 7.0 & $4.7 \%$ & normal & Romania & 20.0 & 6.4 & $-9.1 \%$ & chaos \\
\hline Spain & -3 & 8.1 & $-10.0 \%$ & normal & Serbia & 19.5 & 6.4 & $-10.0 \%$ & normal \\
\hline Jamaica & -3 & 7.0 & $3.6 \%$ & normal & Philippines & 19.0 & 6.7 & $-14.4 \%$ & chaos \\
\hline Japan & -4 & 8.0 & $-9.7 \%$ & normal & Indonesia & 18.0 & 6.4 & $-11.0 \%$ & chaos \\
\hline Poland & -4 & 6.7 & $8.2 \%$ & normal & Venezuela & 15.5 & 3.2 & $75.7 \%$ & restriction \\
\hline Neutral & & & & & Ecuador & 15.0 & 6.3 & $-11.9 \%$ & chaos \\
\hline Iran & -8.5 & 2.5 & $184.5 \%$ & restriction & $++\mathrm{C}-\mathrm{P}$ & & & & \\
\hline Costa Rica & -10 & 8.1 & $-14.6 \%$ & chaos & Malaysia & -39.0 & 6.9 & $-22.9 \%$ & chaos \\
\hline Morocco & -12 & 5.0 & $35.9 \%$ & restriction & Panama & -42.0 & 7.1 & $-27.1 \%$ & chaos \\
\hline Greece & -12.5 & 7.3 & $-7.4 \%$ & normal & Guatemala & -44.5 & 5.6 & $-10.6 \%$ & chaos \\
\hline Uruguay & -12.5 & 8.4 & $-19.4 \%$ & chaos & & & & & \\
\hline
\end{tabular}

$++\mathrm{I}-\mathrm{L}=$ potential strong individual liberal democracy, $\mathrm{I}-\mathrm{L}=$ potential adequate individual liberal democracy, neutral = potential neutral democracy, C-P = potential adequate common professional democracy, $++\mathrm{C}-\mathrm{P}=$ potential strong common professional democracy. 
highest positive deviations are Saudi Arab (225.8\%) and Iran (184.5\%) which are under extremely abnormal threat in the extremely dangerous Middle East. All countries with high positive deviation are under some kind of real or perceived threat. The USA under the threat of terrorism after $9 / 11$ eventually shows the restriction abnormality (10.9\%) in 2016 the United States was downgraded from a full democracy to a flawed democracy. Without real or perceived threat, the political restriction should decrease.

$<-10 \%$ deviation occurs when the expected DI is $<-10 \%$ less than the observed DI which means the country is expected to be more common professional democracy than the observed. These countries have misplaced democracy. Without sufficient individualism with rule of law and liberty to form individualistic and independent individuals, people are loyal to their tribe-party, resulting in bitter tribal wars against one another, resulting in tribalization. The result is chaotic politics. In Table 2, most South American and Asian countries have the high negative deviations which mean political chaos. Under the strong domination of the Western individual liberal democracy, South Korea, Hong Kong (recent), Taiwan, the Middle Eastern countries, African countries, and South American countries turn into tribal politics instead of true individual liberal democracy based on individualism, rule of law, and liberty.

\subsection{Production Energies}

The production energies (driver and amiable energies) from the Production Dimension Model are derived from the combination of masculinity versus femininity (MAS) and uncertainty avoidance index (UAI) from the Cultural Dimension Model. In Masculinity vs. femininity (MAS), high MAS represents a large difference between masculinity and femininity, while low MAS represents a small difference between masculinity and femininity: Masculinity is for achievement, heroism, assertiveness and material rewards for success. Femininity is for cooperation, modesty, caring for the weak and quality of life. In terms of social styles in the social style model (Merrill \& Reid, 1999), masculinity represents task orientation, while femininity represents people orientation. The mental origin of high MAS is strong gender division of labor, while the mental instinct of low MAS is weak gender division of labor. The original source of high MAS is harsh environment which requires strong task orientation, while the original source of low MAS is hospitable environment which does not require strong task orientation.

In the uncertainty avoidance index (UAI), high UAI is uncertainty avoidance, while low UAI is uncertainty tolerance. Societies with uncertainty avoidance prefer clearly defined codes of behavior, guidelines, and laws based on absolute truth. Societies with uncertainty tolerance accept and even welcome different thoughts or ideas and free-flowing environments. Basically, uncertainty avoidance represents passivity with rigid protective boundary, while uncertainty tolerance represents activity with flexible protective boundary. The mental origin 
of high UAI is the strong protective boundary instinct, while the mental origin of low UAI is the weak protective boundary instinct. The original source of uncertainty tolerance (low UAI) is the cultural melting pot with predictable threat from environment and other nations, while the original source of uncertainty avoidance is cultural homogeneity with unpredictable threat from environment and other countries.

MAS and UAI are not correlated. For examples, China has high MAS and low UAI, and Japan has high MAS and high UAI, because both China and Japan face harsh environment for high MAS, and China is a cultural melting pot (56 ethnic groups) for low UAI, while Japan has cultural homogeneity with frequent unpredictable earthquakes for high UAI.

In the production dimension model, the production energies (driver and amiable energies) are derived from the combination of MAS and UAI. The production energies are dualistic with yin and yang consisting of the amiable energy as yin and the driver energy as yang. In terms of social styles in the social style model, the combination of task orientation and activity (tell) with flexible protective boundary is driver, while the combination of people orientation and passivity (ask) with rigid protective boundary is amiable. Likewise, the driver production energy has high MAS and low UAI, while the amiable production energy has low MAS and high UAI. The driver energy produces under high energy condition, while the amiable energy produces under moderate energy condition.

The potential energy index $(\mathrm{PEI})=(\mathrm{MAS}-\mathrm{UAI}) / 2$. The driver energy has high PEI, while the amiable energy has low PEI. The PEI's of countries is listed in Table 3.

\subsection{Production Purposes}

The production purposes (ant and grasshopper purpose) from the Production Dimension Model are derived from the combination of long term orientation versus short term normative orientation (LTO) and indulgence versus restraint (IVR) from the Cultural Dimension Model. In long term orientation versus short term normative orientation (LTO), long-term orientation (high LTO) represents thrift for being sparing with resources, persistence for sustained efforts for slow results, willingness to subordinate oneself for a purpose, and concern with personal adaptiveness, while short-term orientation (low LTO) represents social pressure toward spending, efforts to produce quick results, concern with social and status obligations, and concern with personal stability. The top positions for LTO are occupied by China and Japan and the Four Little Dragons (Hong Kong, Taiwan, South Korea, and Singapore). These countries are under the influence of Confucianism. Continental European countries occupied a middle range. Great Britain and its Anglo partners Australia, New Zealand, the United States, and Canada scored on the short-term side.

As mentioned in Section 2.1.1., the generativity social instinct is the long-term instinctive commitment to future generations. The mental origin of long-term 
Table 3. The potential energy.

\begin{tabular}{cccccc}
\hline & PEI & & PEI & & PEI \\
\hline ++Driver & & Indonesia & -1 & Finland & -16.5 \\
Slovakia & 29.5 & Venezuela & -1.5 & Netherlands & -19.5 \\
Singapore & 20 & Italy & -2.5 & Croatia & -20 \\
China & 18 & Bangladesh & -2.5 & Turkey & -20 \\
Ireland & 16.5 & Denmark & -3.5 & Amiable & \\
Great Britain & 15.5 & Nigeria & -4 & Norway & -21 \\
Hong Kong & 14 & Neutral & & France & -21.5 \\
Philippines & 10 & Tanzania & -5.5 & Belgium & -21.75 \\
Driver & & Mexico & -6.5 & Spain & -22 \\
India & 8 & Morocco & -7.5 & Bulgaria & -22.5 \\
United States & 8 & Saudi Arabia & -7.5 & Peru & -22.5 \\
Malaysia & 7 & Iran & -8 & S Korea & -23 \\
S Africa & 7 & Colombia & -8 & Lithuania & -23 \\
Vietnam & 5 & Czech Rep. & -8.5 & Romania & -24 \\
Australia & 5 & Pakistan & -10 & Serbia & -24.5 \\
Switzerland & 4.5 & Luxembourg & -10 & Malta & -24.5 \\
Austria & 4.5 & Taiwan (China) & -12 & Latvia & -27 \\
New Zealand & 4.5 & Sweden & -12 & El Salvador & -27 \\
Hungary & 3 & Brazil & -13.5 & Greece & -27.5 \\
Canada & 2 & Poland & -14.5 & Russia & -29.5 \\
Germany & 0.5 & Argentina & -15 & $\underline{++ \text { amiable }}$ & -31 \\
\hline & 1.5 & Estonia & -15 & Uruguay & -36.5 \\
\hline
\end{tabular}

++ driver $=$ potential strong driver energy, driver $=$ potential adequate driver energy, neutral $=$ potential neutral energy, amiable $=$ potential adequate amiable energy, ++ amiable $=$ potential strong amiable energy.

orientation is strong generativity social instinct. The original source of long-term orientation is pious genealogical linkage which is important in Confucianism. Many families have shrines for ancestors and genealogy books to go back hundreds years and even thousands years. The most important task in life is to carry on one's ancestral line in order to honor one's ancestors and to benefit one's future generations. Long-term orientation is in terms of generations. Through this pious genealogical linkage, a person becomes immoral with a very long-term goal. The mental origin of short-term orientation is weak generality without significant commitment to future generations. The source of short-term orientation is impious genealogical linkage without significant respect to ancestors and significant commitment to future generations. Short-term orientation is in terms of days and months. 
In Indulgence vs. restraint (IVR), Indulgence stands for a tendency to allow relatively free gratification of basic and natural human desires related to enjoying life and having fun. Its opposite pole, restraint, reflects a conviction that such gratification needs to be curbed and regulated by strict social norms.

The mental origin of indulgence is the emotional brain enjoying life and having fun. The mental origin of restrain is the rational brain curbing enjoyment and fun. The origin of restrain is the consolidative infrastructure in the consolidative agrarian society. The consolidative infrastructure had to be build and maintained constantly by the rational brain with little time for leisure. Societies of hunter-gatherers and horticulturalists were not burdened by the consolidative infrastructure, so people had time for leisure enjoying life and having fun, and to them, the purpose of production was to enjoy life and have fun as the fruit of production.

The production purposes are dualistic with yin and yang consisting of the grasshopper purpose as yin and the ant purpose as yang. The ant purpose to produce with strong firm purpose has the production relations of high LTO (long-term orientation) and low IVR (restrain), while the grasshopper purpose to produce with moderate firm purpose has the production relations of low LTO (short-term orientation) and high IVR (indulgence). The potential purpose in$\operatorname{dex}(\mathrm{PPI})=(\mathrm{LTO}-\mathrm{IVR}) /$.2 . The ant purpose has high PPI, while grasshopper purpose has low PPI. The countries with PPI are listed in Table 4.

\subsection{Production Workforces}

The production workforces consist of dynamic production workforce (driver production energy + ant production purpose) and easygoing production workforce (amiable production energy + grasshopper production purpose). Dynamic workforce has high production energy and high firm production purpose, while easygoing production force has moderate production energy and moderate firm production purpose. The potential workforce index (PWI) is as follows.

$$
\mathrm{PWI}=(\mathrm{PEI}+\mathrm{PPI}) / 2
$$

where $\mathrm{PEI}=$ production energy index and PPI = production purpose index. Dynamic production workforce has high PWI, and easygoing production workforce has low PWI.

The PWI to qualify workforce is potentially a good indicator for the GDP Growth Rate. The developing countries (low GDP per person countries) just started to grow economically few years ago from low GDP per person and basically agricultural society, so they are under economic growth spurt like puberty growth spurt. The developed countries (high GDP per person) have mature economy from high GDP per person, so their growth rates are lower than the growth rates of developing countries. To compare the workforces of developing countries and developed countries on the same level, the PWI's of developing countries are adjusted by the spurt multiplier and industrialization booster constant as follows. 
Table 4. The potential purpose.

\begin{tabular}{|c|c|c|c|c|c|}
\hline Political Unit & $\underline{\mathrm{PPI}}$ & Political Unit & $\underline{\text { PPI }}$ & Political unit & $\underline{\text { PPI }}$ \\
\hline$\underline{++a n t}$ & & Indonesia & 12 & Malta & -9.5 \\
\hline S Korea & 35.5 & Serbia & 12 & Norway & -10 \\
\hline Estonia & 33 & Vietnam & 11 & Peru & -10.5 \\
\hline Lithuania & 33 & France & 7.5 & Sweden & -12.5 \\
\hline China & 31.5 & Poland & 4.5 & Iran & -13 \\
\hline Russia & 30.5 & Switzerland & 4 & Uruguay & -13.5 \\
\hline Latvia & 28 & Luxembourg & 4 & S Africa & -14.5 \\
\hline Bulgaria & 26.5 & Spain & 2 & Canada & -16 \\
\hline Pakistan & 25 & Slovenia & 0.5 & Denmark & -17.5 \\
\hline Slovakia & 24.5 & $\underline{\text { Neutral }}$ & & grasshopper & \\
\hline Japan & 23 & Netherlands & -0.5 & Ireland & -20.5 \\
\hline Hong Kong & 22 & Austria & -1.5 & United States & -21 \\
\hline Taiwan (China) & 22 & Turkey & -1.5 & New Zealand & -21 \\
\hline Germany & 21.5 & Tanzania & -2 & Argentina & -21 \\
\hline Czech Rep. & 20.5 & Greece & -2.5 & Australia & -25 \\
\hline$\underline{\text { Ant }}$ & & Portugal & -2.5 & Trinidad & -33.5 \\
\hline Romania & 16 & Morocco & -5.5 & El Salvador & -34.5 \\
\hline Italy & 15.5 & Thailand & -6.5 & Colombia & -35 \\
\hline Hungary & 13.5 & Philippines & -7.5 & ++ grasshopper & \\
\hline Bangladesh & 13.5 & Brazil & -7.5 & Nigeria & -35.5 \\
\hline Singapore & 13 & Malaysia & -8 & Mexico & -36.5 \\
\hline India & 12.5 & Saudi Arabia & -8 & Venezuela & -42 \\
\hline Croatia & 12.5 & Great Britain & -9 & & \\
\hline
\end{tabular}

++ ant $=$ potential strong ant purpose, ant $=$ potential adequate ant purpose, neutral $=$ potential neutral purpose, grasshopper $=$ potential adequate grasshopper purpose, ++ grasshopper $=$ potential strong grasshopper purpose.

$$
\begin{aligned}
& \mathrm{PWI}_{\text {devloping }} \\
& =\mathrm{PWI} \times \text { growth spurt multiplier }+ \text { industrilization booster constant } \\
& =2 \mathrm{PWI}+70
\end{aligned}
$$

On the other hand, Venezuelan, Iran, and Greece have been under extreme economic difficulty for few years mostly from the external economic pressure, so their PWI's are adjusted by a downturn constant as follows.

$$
\mathrm{PWI}_{\text {downturn }}=\mathrm{PWI}-\text { downturn constant }=\mathrm{PWI}-100
$$

The statistical correlation between PWI and GR (GDP Growth Rate between 2010 and 2019 (Ventura, 2019)) produces the best-fit equation, the deviation between the expected GR and GR, and R2 value. The best-fit equation between PWI and GR and its R2 are shown as follows.

$$
\begin{gathered}
\mathrm{GR}_{\text {exp ected }}=0.0457 \mathrm{PWI}+2.2094 \quad \mathrm{R} 2=0.8 \\
\% \text { deviation }=100 \times\left(\mathrm{GR}_{\text {expected }}-\mathrm{GR}_{\text {observed }}\right) / \mathrm{GR}_{\text {exp ected }}
\end{gathered}
$$


The correlation between PWI and GR is strong $(\mathrm{R} 2=0.8)$. The calculated result for the countries in the Hofstede culture model is shown in Table 5.

Table 5. PWI and the observed GDP growth rate (GR) from 2010 to 2019.

\begin{tabular}{|c|c|c|c|c|c|c|c|c|c|}
\hline political unit & PWI & $\% G R$ & \%deviation & abnormality & political unit & PWI & $\% \mathrm{GR}$ & \%deviation & abnormality \\
\hline$\underline{++ \text { Dynamic }}$ & & & & & Belgium & -4.625 & $1.4 \%$ & $29.9 \%$ & suppressed \\
\hline Slovakia & 27 & $3.2 \%$ & $7.1 \%$ & normal & Poland & -5 & $3.6 \%$ & $-81.7 \%$ & enhanced \\
\hline China & 24.75 & $7.6 \%$ & $0.9 \%$ & normal & Serbia & -6.25 & $1.8 \%$ & $6.4 \%$ & normal \\
\hline Hong Kong (China) & 18 & $3.3 \%$ & $-8.8 \%$ & normal & United States & -6.5 & $2.3 \%$ & $-20.3 \%$ & enhanced \\
\hline Singapore & 16.5 & $5.0 \%$ & $-68.7 \%$ & enhanced & Morocco & -6.5 & $3.5 \%$ & $27.3 \%$ & suppressed \\
\hline Japan & 12.25 & $1.3 \%$ & $53.1 \%$ & suppressed & Canada & -7 & $2.1 \%$ & $-11.1 \%$ & enhanced \\
\hline Germany & 11 & $1.9 \%$ & $29.9 \%$ & suppressed & France & -7 & $1.3 \%$ & $31.2 \%$ & suppressed \\
\hline India & 10.25 & $7.4 \%$ & $-16.6 \%$ & enhanced & Saudi Arab & -7.75 & $3.6 \%$ & $23.4 \%$ & enhanced \\
\hline Dynamic & & & & & New Zealand & -8.25 & $2.8 \%$ & $-52.8 \%$ & enhanced \\
\hline Estonia & 9 & $3.6 \%$ & $-37.4 \%$ & enhanced & Australia & -10 & $2.6 \%$ & $-48.4 \%$ & enhanced \\
\hline Hungary & 8.25 & $2.5 \%$ & $3.3 \%$ & normal & Netherlands & -10 & $1.5 \%$ & $14.4 \%$ & suppressed \\
\hline Vietnam & 8 & $6.3 \%$ & $-2.6 \%$ & normal & Spain & -10 & $1.0 \%$ & $42.9 \%$ & suppressed \\
\hline Pakistan & 7.5 & $4.0 \%$ & $34.4 \%$ & suppressed & Easygoing & & & & \\
\hline Italy & 6.5 & $0.2 \%$ & $92.0 \%$ & suppressed & Denmark & -10.5 & $1.6 \%$ & $7.5 \%$ & normal \\
\hline S Korea & 6.25 & $3.3 \%$ & $-32.3 \%$ & enhanced & Iran & -10.5 & $0.9 \%$ & $48.0 \%$ & suppressed \\
\hline Czech Rep. & 6 & $2.3 \%$ & $7.4 \%$ & normal & Brazil & -10.5 & $1.4 \%$ & $19.1 \%$ & suppressed \\
\hline Indonesia & 5.5 & $5.5 \%$ & $7.0 \%$ & normal & Thailand & -10.75 & $3.7 \%$ & $16.4 \%$ & suppressed \\
\hline Bangladesh & 5.5 & $6.8 \%$ & $-15.0 \%$ & enhanced & Turkey & -10.75 & $5.5 \%$ & $-24.3 \%$ & enhanced \\
\hline Taiwan (China) & 5 & $3.3 \%$ & $-35.4 \%$ & enhanced & Sweden & -12.25 & $2.5 \%$ & $-51.6 \%$ & enhanced \\
\hline Lithuania & 5 & $3.3 \%$ & $-35.4 \%$ & enhanced & Finland & -13 & $1.3 \%$ & $19.5 \%$ & suppressed \\
\hline Switzerland & 4.25 & $1.8 \%$ & $25.1 \%$ & suppressed & Greece & -15 & $-1.9 \%$ & $37.6 \%$ & suppressed \\
\hline Great Britain & 3.25 & $1.8 \%$ & $23.7 \%$ & suppressed & Norway & -15.5 & $1.6 \%$ & $-6.6 \%$ & normal \\
\hline Neutral & & & & & Trinidad & -16 & $-0.3 \%$ & $90.3 \%$ & suppressed \\
\hline Bulgaria & 2 & $2.3 \%$ & $0.0 \%$ & normal & Peru & -16.5 & $4.7 \%$ & $-20.5 \%$ & enhanced \\
\hline Austria & 1.5 & $1.7 \%$ & $25.4 \%$ & suppressed & Malta & -17 & $5.5 \%$ & $-42.7 \%$ & enhanced \\
\hline Philippines & 1.25 & $6.3 \%$ & $-14.1 \%$ & enhanced & Slovenia & -17 & $1.9 \%$ & $-32.6 \%$ & enhanced \\
\hline Latvia & 0.5 & $2.8 \%$ & $-25.4 \%$ & enhanced & ++ Easygoing & & & & \\
\hline Russia & 0.5 & $1.9 \%$ & $14.9 \%$ & suppressed & Argentina & -18 & $1.5 \%$ & $-8.2 \%$ & normal \\
\hline Malaysia & -0.5 & $5.4 \%$ & $-0.7 \%$ & normal & Portugal & -19.5 & $0.6 \%$ & $54.5 \%$ & suppressed \\
\hline Ireland & -2 & $6.4 \%$ & $-22.5 \%$ & enhanced & Nigeria & -19.75 & $3.8 \%$ & $-5.5 \%$ & normal \\
\hline Luxembourg & -3 & $2.9 \%$ & $-39.9 \%$ & enhanced & Mexico & -21.5 & $2.8 \%$ & $18.7 \%$ & suppressed \\
\hline S Africa & -3.75 & $1.8 \%$ & $64.5 \%$ & suppressed & Colombia & -21.5 & $3.7 \%$ & $-7.5 \%$ & normal \\
\hline Tanzania & -3.75 & $6.3 \%$ & $-24.4 \%$ & enhanced & Venezuela & -21.75 & $-7.6 \%$ & $-126.6 \%$ & enhanced \\
\hline Croatia & -3.75 & $0.9 \%$ & $55.8 \%$ & suppressed & Uruguay & -22.25 & $3.3 \%$ & $2.2 \%$ & normal \\
\hline Romania & -4 & $3.0 \%$ & $-48.0 \%$ & enhanced & El Salvador & -30.75 & $2.5 \%$ & $3.8 \%$ & normal \\
\hline
\end{tabular}

++ dynamic $=$ potential strong dynamic workforce, dynamic $=$ potential adequate dynamic workforce, neutral $=$ potential neutral workforce, easygoing $=$ potential easygoing workforce, ++easygoing = potential strong easygoing workforce. 
Most East and South Asian countries have dynamic workforce, and most Nordic and South American countries have easygoing workforce which is also happy workforce. The \% deviation is the deviation of actual GR from the expected GR. Within $\pm 10 \%$ deviation can be considered as normal. The expected GR from PWI is $>10 \%$ greater than the observed GR which means that the economy of a country is suppressed by some other factors than workforce. On the other hand, the expected GR from PWI is $>10 \%$ less than the observed GR means that the economy of a country is enhanced by some other factors than workforce. The most common and important factor other than the potential workforce index (PWI) is the median ages of countries. Japan, Germany, Italy, and some other European countries are among the oldest median age countries in the world, and old people contribute less to economic growth rate in terms of work and spending than young people, so for these countries, the expected GR from PWI is $>10 \%$ greater the observed GR. On the other hand, India has a low median age, so the expected GR is $>10 \%$ less than the observed GR. The political instability and wars can contribute the suppression, such as in Pakistan. China has been a top economic engine (comprising 28\% of global growth in the five years from 2013 to 2018), so in the countries that have significant trade surplus with China, the expected GR is $>10 \%$ less than the observed GR by the enhancement.

The best-fit equation between PWI and DI (Democracy Index) and its R2 are shown as follows.

$$
\mathrm{DI}_{\text {exp ected }}=0.0393 \mathrm{PWI}+7.5194 \quad \mathrm{R} 2=0
$$

The potential workforce index has no correlation with the Democracy Index (R2 $=0)$.

The summary of the production dimension model is listed in Table 6.

The production dimensions for the top GDP countries are listed in Table 7.

Table 6. The production dimension model.

\begin{tabular}{|c|c|c|c|c|c|}
\hline Production Forces & Production force yin-yang & $\begin{array}{l}\text { Production } \\
\text { relations }\end{array}$ & Hofstede model & $\begin{array}{l}\text { Major social } \\
\text { instincts }\end{array}$ & $\begin{array}{c}\text { Original sources of } \\
\text { production people and places }\end{array}$ \\
\hline \multirow{4}{*}{$\begin{array}{l}\text { Production type } \\
\text { (what to produce) }\end{array}$} & $\begin{array}{l}\text { Yang = adventurous } \\
\text { production type (Individual }\end{array}$ & individualism & $\begin{array}{l}\text { Individualism } \\
\text { (high IDV) }\end{array}$ & Extended outgroup & Nomadic pastoral-trade society \\
\hline & liberal democracy) & liberty & $\begin{array}{l}\text { Low power distance } \\
\text { (low PDI) }\end{array}$ & liberty & $\begin{array}{l}\text { The expansion of } \\
\text { individualism for mega nations }\end{array}$ \\
\hline & \multirow{2}{*}{$\begin{array}{l}\text { Yin }=\text { consolidative } \\
\text { production type (Common } \\
\text { professional democracy) }\end{array}$} & collectivism & $\begin{array}{l}\text { Collectivism } \\
\text { (low IDV) }\end{array}$ & Extended ingroup & $\begin{array}{l}\text { Settled consolidative agrarian } \\
\text { society }\end{array}$ \\
\hline & & $\begin{array}{l}\text { Division of } \\
\text { professional }\end{array}$ & $\begin{array}{l}\text { High power distance } \\
\text { (high PDI) }\end{array}$ & $\begin{array}{l}\text { Division of } \\
\text { professional }\end{array}$ & $\begin{array}{l}\text { The expansion of collectivism } \\
\text { for mega nations }\end{array}$ \\
\hline \multirow{2}{*}{$\begin{array}{l}\text { Production energy } \\
\text { (how much to } \\
\text { produce) }\end{array}$} & \multirow{2}{*}{$\begin{array}{l}\text { Yang = Driver production } \\
\text { energy }\end{array}$} & Task orientation & $\begin{array}{l}\text { Masculinity } \\
\text { (high MAS) }\end{array}$ & $\begin{array}{l}\text { Strong gender } \\
\text { division of labor }\end{array}$ & Harsh environment \\
\hline & & Flexible boundary & $\begin{array}{l}\text { Uncertainty tolerance } \\
\text { (low UAI) }\end{array}$ & $\begin{array}{l}\text { weak protective } \\
\text { boundary }\end{array}$ & $\begin{array}{l}\text { Cultural melting pot and } \\
\text { predictable threat from other } \\
\text { nations and nature }\end{array}$ \\
\hline
\end{tabular}




\begin{tabular}{|c|c|c|c|c|c|}
\hline & \multirow{2}{*}{$\begin{array}{l}\text { Yin = Amiable production } \\
\text { energy }\end{array}$} & $\begin{array}{l}\text { People } \\
\text { orientation }\end{array}$ & $\begin{array}{l}\text { Femininity } \\
\text { (low MAS) }\end{array}$ & $\begin{array}{l}\text { Weak gender } \\
\text { division of labor }\end{array}$ & Hospitable environment \\
\hline & & Rigid boundary & $\begin{array}{l}\text { Uncertainty avoidance } \\
\text { (high UAI) }\end{array}$ & $\begin{array}{l}\text { Strong protective } \\
\text { boundary }\end{array}$ & $\begin{array}{l}\text { Homogeneity and uncertain } \\
\text { threat from other nations and } \\
\text { nature }\end{array}$ \\
\hline \multirow{4}{*}{$\begin{array}{l}\text { Production purpose } \\
\text { (why to produce) }\end{array}$} & \multirow{2}{*}{$\begin{array}{l}\text { Yang = Ant production } \\
\text { purpose }\end{array}$} & Long-term goal & $\begin{array}{l}\text { long-term orientation } \\
\text { (high LTO) }\end{array}$ & Strong generativity & Pious genealogical linkage \\
\hline & & Duty orientation & $\begin{array}{l}\text { Low indulge } \\
\text { (low IVR) }\end{array}$ & rational brain & $\begin{array}{l}\text { Consolidative production } \\
\text { infrastructure }\end{array}$ \\
\hline & \multirow{2}{*}{$\begin{array}{l}\text { Yin = Grasshopper } \\
\text { production purpose }\end{array}$} & Short-term goal & $\begin{array}{l}\text { short-term orientation } \\
\text { (low LTO) }\end{array}$ & weak generativity & Impious genealogical linkage \\
\hline & & Leisure orientation & $\begin{array}{l}\text { High indulge (high } \\
\text { IVR) }\end{array}$ & Emotional brain & $\begin{array}{l}\text { Moderate production } \\
\text { infrastructure }\end{array}$ \\
\hline
\end{tabular}

Table 7. The top GDP countries.

\begin{tabular}{|c|c|c|c|c|c|c|c|c|c|}
\hline political unit & PTI & potential type & $\begin{array}{l}\text { potential } \\
\text { democracy }\end{array}$ & PEI & $\begin{array}{c}\text { potential } \\
\text { energy }\end{array}$ & PPI & potential purpose & PWI & $\begin{array}{l}\text { potential } \\
\text { workforce }\end{array}$ \\
\hline United States & 25.5 & ++ adventurous & $++\mathrm{I}-\mathrm{L}$ & 8 & driver & -21 & grasshopper & -6.5 & neutral \\
\hline China & -30 & consolidative & C-P & 18 & ++ driver & 31.5 & ++ ant & 24.75 & ++ dynamic \\
\hline Japan & -4 & adventurous & $\mathrm{I}-\mathrm{L}$ & 1.5 & driver & 19.5 & ++ ant & 10.5 & ++ dynamic \\
\hline Germany & 16 & ++ adventurous & $++\mathrm{I}-\mathrm{L}$ & 0.5 & driver & 21.5 & ++ ant & 11 & ++ dynamic \\
\hline India & -14.5 & neutral & neutral & 8 & driver & 12.5 & ant & 10.25 & ++ dynamic \\
\hline United Kingdom & 27 & ++ adventurous & $++\mathrm{I}-\mathrm{L}$ & 15.5 & ++ driver & -9 & neutral & 3.25 & dynamic \\
\hline France & 1.5 & adventurous & $\mathrm{I}-\mathrm{L}$ & -21.5 & amiable & 7.5 & ant & -7 & neutral \\
\hline Italy & 13 & ++ adventurous & $++\mathrm{I}-\mathrm{L}$ & -2.5 & driver & 15.5 & ant & 6.5 & dynamic \\
\hline Brazil & -15.5 & neutral & neutral & 0 & driver & -7.5 & neutral & -3.75 & neutral \\
\hline Canada & 20.5 & ++ adventurous & $++\mathrm{I}-\mathrm{L}$ & 2 & driver & -16 & neutral & -7 & neutral \\
\hline Russia & -27 & consolidative & C-P & -29.5 & amiable & 30.5 & ++ ant & 0.5 & neutral \\
\hline Korea, South & -21 & consolidative & C-P & -23 & amiable & 35.5 & ++ ant & 6.25 & dynamic \\
\hline Spain & -3 & adventurous & $\mathrm{I}-\mathrm{L}$ & -22 & amiable & 2 & ant & -10 & neutral \\
\hline Australia & 26 & ++ adventurous & $++\mathrm{I}-\mathrm{L}$ & 5 & driver & -25 & ++ grasshopper & -10 & neutral \\
\hline Mexico & -25.5 & consolidative & C-P & & & -36.5 & ++grasshopper & & \\
\hline Indonesia & -32 & consolidative & C-P & -1 & driver & 12 & ant & 5.5 & ++ dynamic \\
\hline Netherlands & 21 & ++ adventurous & $++\mathrm{I}-\mathrm{L}$ & -19.5 & neutral & -0.5 & neutral & -10 & neutral \\
\hline Saudi Arabia & -21 & consolidative & $\mathrm{C}-\mathrm{P}$ & -7.5 & neutral & -8 & neutral & -7.75 & neutral \\
\hline Turkey & -14.5 & neutral & neutral & -20 & neutral & -1.5 & neutral & -10.75 & easygoing \\
\hline Switzerland & 21.5 & ++ adventurous & $++\mathrm{I}-\mathrm{L}$ & 8 & driver & 4 & ant & 6 & dynamic \\
\hline Taiwan (China) & -20.5 & consolidative & $\mathrm{C}-\mathrm{P}$ & -12 & neutral & 22 & ++ ant & 5 & dynamic \\
\hline Poland & -4 & adventurous & $\mathrm{I}-\mathrm{L}$ & -14.5 & neutral & 4.5 & ant & -5 & neutral \\
\hline Thailand & -22 & consolidative & C-P & -15 & neutral & -6.5 & neutral & -10.75 & easygoing \\
\hline Sweden & 20 & ++ adventurous & $++\mathrm{I}-\mathrm{L}$ & -12 & neutral & -12.5 & neutral & -12.25 & easygoing \\
\hline
\end{tabular}


Continued

\begin{tabular}{|c|c|c|c|c|c|c|c|c|c|}
\hline Belgium & 8.5 & adventurous & I-L & -16.5 & neutral & 12.5 & ant & -2 & neutral \\
\hline Iran & -8.5 & neutral & neutral & -8 & neutral & -13 & neutral & -10.5 & easygoing \\
\hline Austria & 22 & ++ adventurous & $++\mathrm{I}-\mathrm{L}$ & 4.5 & driver & -1.5 & neutral & 1.5 & neutral \\
\hline Nigeria & -28.5 & consolidative & C-P & -4 & driver & -35.5 & ++ grasshopper & -19.75 & ++easygoing \\
\hline Argentina & -1.5 & adventurous & $\mathrm{I}-\mathrm{L}$ & -15 & neutral & -21 & ++grasshopper & -18 & ++easygoing \\
\hline United Arab Emirates & -21 & consolidative & C-P & -7.5 & neutral & -8 & neutral & -7.75 & neutral \\
\hline Norway & 19 & ++ adventurous & $++\mathrm{I}-\mathrm{L}$ & -21 & amiable & -10 & neutral & -15.5 & easygoing \\
\hline Israel & 20.5 & ++ adventurous & $++\mathrm{I}-\mathrm{L}$ & -17 & neutral & & & & \\
\hline Hong Kong (China) & -21.5 & consolidative & C-P & 14 & ++ driver & 22 & ++ ant & 18 & ++ dynamic \\
\hline Ireland & 21 & ++ adventurous & $++\mathrm{I}-\mathrm{L}$ & 16.5 & ++ driver & -20.5 & grasshopper & -2 & neutral \\
\hline Malaysia & -39 & ++ consolidative & $++\mathrm{C}-\mathrm{P}$ & 14 & ++ driver & 13 & ant & 13.5 & ++ dynamic \\
\hline Singapore & -27 & consolidative & C-P & 20 & ++ driver & 13 & ant & 16.5 & ++ dynamic \\
\hline South Africa & 8 & adventurous & I-L & 7 & driver & -14.5 & neutral & -3.75 & neutral \\
\hline Philippines & -31 & consolidative & C-P & 10 & ++ driver & -7.5 & neutral & 1.25 & neutral \\
\hline Denmark & 28 & ++ adventurous & $++\mathrm{I}-\mathrm{L}$ & -3.5 & driver & -17.5 & neutral & -10.5 & easygoing \\
\hline Colombia & -27 & consolidative & C-P & -8 & neutral & -35 & ++ grasshopper & -21.5 & ++easygoing \\
\hline Bangladesh & -30 & consolidative & C-P & -2.5 & driver & 13.5 & ant & 5.5 & dynamic \\
\hline Egypt & -21 & consolidative & C-P & -7.5 & neutral & -3 & neutral & -5.25 & neutral \\
\hline Chile & -20 & neutral & neutral & -29 & amiable & & & & \\
\hline Pakistan & -20.5 & consolidative & C-P & -10 & neutral & 25 & ++ ant & 7.5 & ++ dynamic \\
\hline Finland & -20.5 & consolidative & C-P & -16.5 & neutral & -9.5 & neutral & -13 & easygoing \\
\hline Vietnam & -25 & consolidative & C-P & 5 & driver & 11 & ant & 8 & dynamic \\
\hline Czech Republic & 0.5 & adventurous & $\mathrm{I}-\mathrm{L}$ & -8.5 & neutral & 20.5 & ++ ant & 6 & dynamic \\
\hline Romania & -30 & consolidative & C-P & -24 & amiable & & & & \\
\hline Portugal & -18 & neutral & neutral & -36.5 & ++ amiable & -2.5 & neutral & -19.5 & ++easygoing \\
\hline Peru & -24 & consolidative & C-P & -22.5 & amiable & -10.5 & neutral & -16.5 & easygoing \\
\hline Iraq & -21 & consolidative & C-P & -7.5 & neutral & 4 & ant & -1.75 & neutral \\
\hline Greece & -12.5 & neutral & neutral & -27.5 & amiable & -2.5 & neutral & -15 & easygoing \\
\hline New Zealand & 28.5 & ++ adventurous & $++\mathrm{I}-\mathrm{L}$ & 4.5 & driver & -21 & grasshopper & -8.25 & neutral \\
\hline Qatar & -21 & consolidative & C-P & -7.5 & neutral & -8 & neutral & -7.75 & neutral \\
\hline Algeria & -21 & consolidative & C-P & -7.5 & neutral & -8 & neutral & -7.75 & neutral \\
\hline Hungary & 17 & ++ adventurous & $++\mathrm{I}-\mathrm{L}$ & 3 & driver & 13.5 & ant & 8.25 & dynamic \\
\hline Kuwait & -21 & consolidative & C-P & -7.5 & neutral & -8 & neutral & -7.75 & neutral \\
\hline Slovakia & -26 & consolidative & C-P & 29.5 & ++ driver & 24.5 & ++ ant & 27 & ++ dynamic \\
\hline
\end{tabular}

$\mathrm{I}-\mathrm{L}=$ individual liberal democracy, $\mathrm{C}-\mathrm{P}=$ common professional democracy.

\section{The Production Evolution}

The production evolution is connected to human biological evolution (Chung, 
(2018c) as the starting point of the production evolution. During the production evolution, the production stages are transformed by the technological revolutions, including the Upper Paleolithic, Agrarian-Pastoral, Bronze, Iron, Industrial, and Intelligence Revolutions to bring about the six different production stages: the interdependent hunter-gatherer band, split agrarian-pastoral tribe, split individualistic-collectivistic nation, split individualistic-collectivistic mega nation, split individualistic-collectivistic democracy, and interdependent eusocial democracy stages, respectively. In the production evolution, the most important production force is the productions types consisting of adventurous production type and consolidative production type. The most important production relations among production people and places are individualism-collectivism and high-low power distance.

Marxism explains evolution by dialectic. Hegelian dialectic comprises comprising three dialectical stages of development: a thesis, giving rise to its reaction; an antithesis, which contradicts or negates the thesis; and the tension between the two being resolved by means of a synthesis. The production evolution is explained by technological historic dialectic where the production evolution is driven by new technologies from technological revolutions. In technological historical dialectic, thesis is an old technology with old established political system, antithesis is a new technology without established political system, and synthesis is the new technology with new established political system. New technology is derived from technological revolution. For an example, thesis is stone technology and small egalitarian territorial band political system in the hunter-gatherer band stage. Antithesis is pastoral-agrarian technology without established political system. The synthesis is the pastoral-agrarian technology with large hierarchical territorial tribal political system in the split tribe stage.

Political system includes size, ruling-proletariat classes, production type, worldview, and rules. The technologies from technological revolutions increase the economic surplus which leads to the increase in political size in the order of band, tribe, nation, mega nation, split East-West, and the interconnected world. New political system has new ruling class and proletariat class to form class conflict as described in Marxism.

Class conflict in dialectic is usually considered as the consequence of power control. However, if we consider that food and shelter resulted from complex technology in complex social structure are quite unstable due to natural and man-made disasters, class conflict between ruling class and proletariat class is effectively a survival competition to be the last class to survive due to basically unstable source of food and shelter. Proletariat revolutions have occurred more often during food shortage. The instability was severe before industrialization, and is much less severe after industrialization. In effect, industrialization turns class conflict into class mobility. Class conflict is inversely proportional to affluence. Without the constrain of complex technology, the source of food and shelter was actually quite stable in the pre-historic hunter-gatherer society which is considered as affluent society without class conflict as described by Marshall 
Sahlins' “The Original Affluent Society” (Sahlins, 1968).

\subsection{Human Biological Evolution}

Around 6 millions of years ago, a major climate change reduced some part of forested area in Africa to woodland where Ardi (Ardipithecus ramidus) (White et al., 2009) was evolved. Ardi, the oldest human ancestor (4.4 million year old) discovered, lived on woodland. Similar to other apes, Ardi's skull encased a small brain - 300 to $350 \mathrm{cc}$. She lived in the mixed habitat of grassy woodland with patches of denser forest, and freshwater springs. The appearance of woodland caused the evolution from the human-chimpanzee-bonobo common ancestor to produce the bipedal human ancestors, the early hominins. Woodland allowed increasingly amount of food from bushes and low branches, which could be seen and reached from the ground. According to the observation (Carvalho et al., 2012) in Africa, chimpanzees today move on two legs most often when feeding on the ground from bushes and low branches. When food resources are scarce or unpredictable, chimpanzees use upright locomotion to improve food carrying efficiency. It suggests that the same might have occurred among the early hominins. Comparing to forest area, woodland area had scarcer food resources.

For reaching food from low branches on woodland and to carry food, the early hominins came down to the ground partly (not entirely) from living among trees, and adopted bipedalism as the way to move on the ground. However, Ardi's foot was primitive with an opposable big toe that could not provide a push needed for efficient bipedal walking. Ardi had a more primitive walking ability than later hominins, and Ardi had a somewhat awkward gait when on the ground. Its feet were still adapted for grasping trees rather than walking for long distances and running fast on the ground. (For apes, the quadrupedal knuckle-walking like gorillas, bonobos, and chimpanzees was faster and better way than Ardi's primitive awkward bipedalism to move on the ground.) The movement handicap of bipedalism on the ground was serious for very young, very old, and pregnant early hominins. To the early hominins in the mixed habitats, the area with many tall trees was the safe home area where very young, very old, and pregnant hominins stayed, and where they could escape quickly to the safety in tall trees, and the area with few tall trees was the unsafe exploration area for the exploration to find extra foods that could not be found in the safe home area. The two free hands from bipedalism allowed the early hominins to carry a large quantity of food home from the exploration as proposed by C. Owen Lovejoy (Lovejoy, 2009) and to carry simple defensive weapons such as sticks and stones to defense against large predators in the unsafe area. The exploration also allowed them to scavenge meats left by carnivores.

Consequently, the bipedalism and the mixed habitat divided the early hominins into the interdependent specialists which were the homemaker-forager who took care of children and foraged in the safe home forest area and the adventur- 
ist-forager who explored and foraged in the unsafe exploration woodland area. A good homemaker-forager was able to do multitask and navigate through landmarks (different trees) as women today. A good explorer-forager was able to have a good sense of direction (orientation in space) for exploration and strong upper body strength to carry foods and defensive weapons as men today. The homemaker-forager included both fertile homemaker-forager and infertile homemaker-forager. Women today become infertile after menopause at about the age of 51. A today woman's best reproductive years are in her 20s. Fertility gradually declines in the 30 s, particularly after age 35 . The division of labor allowed the early hominins to take full advantage of the mixed habitat in terms of security and food procurement.

Such interdependent specialists group produced theory of mind (mind-reading) that recognizes that the others exist to think for themselves. Theory of mind is derived from theory of specialty (specialty-reading) in interdependent specialists group where each specialist has its own specialty of work and work plan. In theory of specialist, each specialist must recognize that each specialist has its own specialty different from the specialties of other specialists, and each specialist has its own work plan distinctively different from the work plans of other specialists. To work together interdependently, all specialists must have theory of specialist in order to avoid overlapping unproductively and dangerously each other's work. Theory of specialty turned into theory of mind where specialty was replaced by the mind of each person. In theory of generality, each generalist does not need to distinctively recognize the types of work and work plans of other generalists, because they are not distinctively different. As a result, theory of generality does not turn into theory of mind. Theory of mind is the base of mind-reading mentalization (Fonagy et al., 2002) which is the base of interdependent sociality. Interdependence required gentle temperament toward one another for interdependent relationship. Gentle temperament was shown in the disappearance of sharp canine teeth in early human ancestors as the only apes without sharp canine teeth for internal fighting.

The further gradual drying turned the mixed forest-woodland habitat into the mixed woodland-savanna habitat. Early Homos, such as Homo habilis and Homo naledi, lived in the mixed woodland-savanna habitat. They were good at tree-climbing and bipedal walking, and could run better than early hominins. Upon further drying, Middle Homos, such as Homo erectus, lived in savanna habitat originally. Without the foods from woodland, they had division of labor with the gatherer group to gather plant foods and the hunter group to hunt animals for meat. They were good at bipedal walking and running, but not tree climbing. The production type for hunters is adventurous production type which is high risk and high nutrition (high-profit) to hunt unpredictable and dangerous food targets, while the production type for gatherers is consolidative production type which is low risk and low nutrition (low-profit) to collect predictable and safe food targets. In the interdependent division of labor, hunters and gatherers understand each other through theory of mind, and share foods 
together. Homo erectus had medium size brains. The brain size increase was due to the intake of nutritious meat to supply energy and fat for the expanding energy-fat hungry brain. The period between 800,000 and 200,000 years ago is the period of strongest climate fluctuation worldwide, resulting in adverse habitat that endangered the existence of Homos. To increase reproductive success under such evolutionary pressure, the brain size increased. The result was the emergency of late Homos, such as Homo sapiens and Neanderthals. The production evolution started with interdependent cooperative hunter-gatherer band which is the cooperative primitive communism in Marxism.

\subsection{The Interdependent Linked Hunter-Gatherer Band Stage by the Upper Paleolithic Revolution}

The Upper Paleolithic Revolution transformed the original interdependent non-interactive hunter-gatherer band stage starting from about 200,000 years ago into the interdependent linked hunter-gatherer band stage starting about 40,000 years ago. A band society of hunter-gatherers was the simplest form of human society. Their power structure is egalitarian. A band generally consists of a small group ranging from 30 to 50 people (Zatrev, 2014). The human social brain can instinctively manage the social group size of about 150 people (Dunbar's Number) (Dunbar, 1993), so before the linked band stage, people in a band from 30 to 50 people could instinctively deal with several bands at the same time. There was no evidence for extensive religious practice (Wunn, 2000), so from about 200,000 to about 40,000 years ago, humans were irreligious, basically, because there was no need for religion.

During the Upper Paleolithic Period, a number of sudden temperature drops reduced significantly the area for forest in Europe and Asia. The Neanderthal became extinct during this period. The reduction of forest reduced the food supply, usable timber, and other non-food materials. The reduction of the number of trees forced humans to look for alternatives to wood to make tools. The new tools used bone, antler, and ivory. During this time, humans also learned to apply heat to clay objects in order to harden them. Humans also made advanced tools including fish hooks, rope, oil lamps, and eyed needles. The invention of complex tool led to the Upper Paleolithic Revolution in the Upper Paleolithic Period between 10,000 and 40,000 years ago before the Agricultural Revolution. Similar to the Industrial and Agricultural Revolutions, the Upper Paleolithic Revolution during the Upper Paleolithic period represents a short time span when numerous inventions appeared and cultural changes occurred (Bar-Yosef, 2002).

The invention of complex tools required a large network of production and trade. The interaction among many bands in this large network of production and trade was reinforced by the new religions. During the Upper Paleolithic Period, the new religions of female figurines (Dixson \& Dixson, 2011) and cave paintings (Lewis-Williams, 2002) based on imaginary theory of mind were developed. The enormous distribution of these female figurines implied a ritualis- 
tic exchange system with the figurines playing a central role in intergroup relations (Cunliffe, 2001). The new religions that reinforced the interaction among bands allowed people to deal with the population much more than 150 people (Dunbar's Number). The Upper Paleolithic Revolution resulted in the linked band stage.

Religions became necessary and permanent part of stable linked band social structure. Without religious imagination (Wunn, 2000), the Neanderthal became extinct during this period. The religions in the linked band stage included animism, afterlife, and shamanism. Female figurines and cave paintings are animism. Peoples, Duda, and Marlowe found the oldest trait of religion, present in the most recent common ancestor of present-day hunter-gatherers, was animism. Belief in an afterlife emerged, followed by shamanism. Ancestor worship and high gods who are active after the Upper Paleolithic Period were absent in early hunter-gatherer, suggesting a deep history for the egalitarian nature of hunter-gatherer societies (Peoples, Duda, \& Marlowe, 2016). The pre-civilized small hunter-gatherer bands had rigid boundary without material surplus for material accumulation, so the pre-civilized production relation was territorialism, the production type was the subsistent production type, and the political type was egalitarianism. In Marxism, the linked band stage is the primitive communism mode.

\subsection{The Split Agrarian-Pastoral Tribe Stage by the Agrarian-Pastoral Revolution}

The Agrarian-Pastoral Revolution (Neolithic Revolution) started at different times at different parts of the world. The earliest started about 12,000 years ago in the Southwestern Asia. The causes of the Agricultural Revolution may have varied from region to region. The Levant saw the earliest developments of the Neolithic Revolution from around 12,000 years ago, followed by sites in the wider Fertile Crescent around 11.000 years ago. India 11,000 years ago, the Yangtze and Yellow River basins 9000 years ago, and Egypt around 6500 years ago. The Agricultural Revolution through the domestication of plants and animals marked the transition in human history from small nomadic bands of hunter-gatherers to larger agricultural and pastoral settlements and early civilization.

The agrarian-pastoral technological revolution split the hunter-gatherer bands into settled agrarian tribes on fertile agrarian land and nomadic pastoral tribe on arid pastoral land. An exchange system grew up between agrarian tribes and pastoral tribes for the products such as hides, wool, milk, meat, horn and bone, and live animals from pastoral tribes for grain, peas, crafts, and tools from agrarian tribes. The exchange allowed some nomadic pastoralists to become nomadic traders to form nomadic pastoral-trade tribes. Most of the time, relations between settled agriculturalists and nomadic pastoralists-traders were harmonious with rigid boundary. The large differences in lifestyles and lands allowed settled agriculturalists and nomadic pastoralists-traders to stay in separate places 
peacefully without mixing for a very long time, resulting in distinctively different races between agriculturalists and pastoralists-traders.

Settled agriculturalists and nomadic pastoralists-traders developed different production types. The arid pastoral land brought about adventurous production type with high-profit, high risk, and low coordination frequent migration, military plundering, and risky nomadic long-distant trade. The production relation among pastoralists-traders was individualism which required individual independence in adventurous production type. The fertile agrarian land produced consolidative production type with consolidative, low risk, and high coordination agrarian irrigation and infrastructure. The production relation among agriculturalists was collectivism which required collective interdependence in consolidative production type. With rigid boundary between agriculturalists and pastoralists-traders, the worldview was still territorialism. The worldview of pastoralists-traders was individualistic territorialism, while the worldview of agriculturalists was collectivistic territorialism. The political type was tribalism ruled by tribal chiefs. In Marxism, the split tribe stage is the slave state mode ruled by tribal chiefs as absolute masters.

The egalitarian religions during the linked bands stage were transformed into hierarchical ancestor worship and high gods. Ancestor worship is defined as belief that the spirits of ancestors remain active in another realm where they may influence the living, and can be influenced by the living (Steadman, Palmer, \& Tilley, 1996). Ancestor worship allowed the hierarchical social structure to be inherited. "High gods" is defined as single, all-powerful creator deities who may be active in human affairs and supportive of human morality (Swanson, 1960). Ancestor worship and high gods appointed hierarchical social structures. Each tribe had one dominant ancestor or high god.

\subsection{The Split Individualistic-Collectivistic Nation Stage by the Bronze Revolution}

The Bronze Age started at different times at different parts of the world. The earliest started about 5500 years ago in the Southwestern Asia. The Bronze Age ended about 3000 years ago when the Iron Age started. The bronze technological revolution led to the invention of vehicles with spoked wheels for long-distant battle and chariots for effective weapon which effectively destroyed the boundary between the agrarian tribe and the pastoral tribe resulting in the transformation from split tribes into nations consisting of both pastoral tribes and agrarian tribes. From their homeland north of the Black Sea and the Caspian Sea between 5000 and 4800 years ago, the nomadic Yamnaya pastoralists who domesticated horses and then developed wheeled vehicles and chariots, invaded and mixed with agriculturalists, and become the ancestors of a group of people who spoke Indo-European language, including most European languages (Greek, Latin, the Romance languages of French, Spanish, Portuguese and Italian, and the Germanic, Scandinavian and Slav languages), Iranian and several languages in South Asia (Anthony, 2010). In the Middle East, the Semitic pasto- 
ralists in the large, arid desert west of Mesopotamia, stretching south from Syria into the Arabian Peninsula swept over the more fertile lands of Sumeria and what became known as Canaan and Palestine (Hetzron, 1997).

The merge of pastoralists and agriculturalists transformed the split tribe stage into the split nation stage. Nations consisted of both agriculturalist culture and pastoralist culture. The nations were split into the collectivistic nations dominated and ruled by collectivism culture and the individualistic nations dominated and ruled by individualism culture.

The collectivistic nations were dominated by consolidative production type with consolidative, low risk, and high coordination agrarian irrigation and infrastructure. The boundaries among nations were flexible, so the production relation was collectivism without territorialism, and the political production type was collectivistic authoritarianism. The nations in the East originated from India and China were dominated by consolidative production type and authoritarian collectivism.

Nation is much more complex than tribe. Since collectivism is the worldview of extended ingroup where relation in ingroup is important, it was necessary to establish explicit rule of relation to rule complex collective nations. All people had explicit and clear relations with one another. Rule of relation (Jiang, Lo, \& Garris, 2012; Chung, 2020) is derived from rule of intragroup including commitment, reciprocity, division of labor, and generativity. Rule of relation is the basic source of morality. The core rule of collective nation was rule of relation. At the same time, all nations consisted of both collectivism and individualism. It was necessary to have rule of law (Haakonssen, 1996; Chung, 2020) which is the rule of outgroup where all adult individuals are considered as independent individuals without relations. Under rule of law, all adult individuals are independent and equal. As a result, the core production relations of collective nations were collectivism and rule of relation, and the complementary production relations were individualism and rule of law. All nations had core production relations and complementary production relations.

The individualistic nations were dominated by adventurous production type with adventurous, high risk, and low coordination frequent military expansion, military plundering, and risky long-distant trade and the individualism production relation. The production relation was individualism, and the political type was individualistic feudalism. The nations in the West originated from the Middle East and Greece were dominated by adventurous production type and individualism. In Marxism, the split nation stage is the feudalism mode. The core production relations of individualistic nations were individualism and rule of law, such as the Mosaic Law, and the complementary production relations were collectivism and rule of relation.

In terms of perception, individualism worldview percept an objects as identity standing alone, collectivism worldview percept an object to have relation with another object. As a result, the Westerners with individualism worldview pay attention to the focal object separated from its surrounding based on individualis- 
tic perception, while the Easterners with collectivism worldview attend more broadly to the overall surroundings and to the relations between the object and the field (Nisbett, 2004; Yuki et al., 2005). One typical way to identify the East vs. the West is to pair panda, monkey, and banana. Typically, the Westerners pair panda and monkey for the same category (animals), while the Easterners pair monkey and banana for the relationship (monkey eats banana). Because of the differences in perception, it is important for the Westerners and the Easterners to have theory of mind to recognize, respect, and understand each other's mind.

During the split nation stage, the religion was polytheism. In polytheism, the chief deity was typically remote, and people worshiped their local deities. One typical example of polytheism is the polytheism in Canaan. Canaan, an ancient region between the River Jordan and the Mediterranean, located in the Levant region of present-day Lebanon, Syria, Jordan, and Israel. The chief deity was El. During the Bronze Age and the early Iron Age, each tribe had its own local tribal deity under El as el in the word of Israel (Davies, 2010). Israel and Judah shared Yahweh as their tribal god. The various tribal gods were more or less equal. Because of the intermarriages and alliance among these tribes, each tribe had altars for the national gods of neighboring tribes. According to archeological evidence (Stern, 2001), during this time, idols represented other religions were found commonly in Jewish homes.

\subsection{The Split Individualistic-Collectivistic Mega Nation Stage by the Iron Revolution}

The Iron Age (the Iron Revolution) started between 1200 BCE and $600 \mathrm{BCE}$, depending on the region. Iron is tougher and lighter than bronze and was used to make much better sharp objects like spears, swords, and sharp tools than bronze. The source for iron was much more abundant than bronze. The state with iron technology was strong enough with enough destructive power of iron weapons to form mega nations such as mega empires. The earliest proto-mega centralized empire is the Hittite Empire based on the advantages entailed by its high advancement on ironworking at the time (Muhly, 2003). The Hittite Empire was not very large, and did not last long. The earliest mega centralized empires were the neo-Assyrian empire (934-609 BCE) and neo-Babylonian empire (612-539 BCE). In some regions, such as China, the late bronze period and the early iron period were overlapped, so mega empires were formed in the late bronze period, and completely solidified in the iron period.

The Iron Technological Revolution transformed the split nation stage into the split mega nation stage. The mega nations were split into collectivistic mega nations and individualistic mega nations. Nations were broadened into mega nations, so collectivism in collectivistic authoritarianism and individualism in individualistic feudalism had to be also broadened. Collectivism broadened by division of professional to transform collectivism from authoritarian collectivism ruled by aristocrats into professional collectivism ruled by elite professionals. The political type was elite meritocracy which was practiced in India and China. 
Individualism was broadened by liberty to transform individualism from feudal individualism into liberal individualism ruled by majority of elite nobilities, landowners, traders, and industrialists. The political type was elite capitalism. Such broadening constituted the Axial Age from about the 8th to the 3rd century BCE (Joas \& Bellah, 2012) and later again the Enlightenment. In Marxism, the split mega nation stage is the capitalism mode.

Collectivism broadened by division of professional to transform collectivism from authoritarian collectivism ruled by aristocrats into professional collectivism ruled by elite professionals. In China the first emperor in the decentralized China is $\mathrm{Yu}$ the Great (2123-2025 BCE) as the founder of Xia Dynasty (2070-1600 BCE). Yu the Great was a professional engineer who became a professional ruler because he introduced flood control benefiting people. Yu successfully devised a system of flood controls that relieved flood water, provided irrigation, and dredged riverbed. The tradition of professional rulers became an important part of Chinese traditions. The Han dynasty (206 BCE-220 CE) established meritocracy. All high administrators in government had to be professionally qualified through the national examination system and the national promotion system (Tan \& Geng, 2005). All princes had to be educated and trained to be professional rulers.

In India, the Varna (caste) system was meritocracy based on division of professional consisting of Brahmin Varna for priests and thinkers, Kshatriya Varna for rulers and warriors, Vaishya Varna for merchants and skill workers, and Shudra Varna for labors. "Varna" means one that is adopted by choice. Everyone is considered to be born as Shudra. Through education, one becomes a Brahmin, Kshatriya or Vaishya. This completion of education is considered to be a second birth to obtain the status of "Dwija" (twice-born) for a Brahmin, Kshatriya or Vaishya. However, due to frequent foreign invasions, the Varna system became more rigid to protect the Varna system from the foreign invaders (Newar, 2016).

The Varna system is derived from the professional system in the earlier agrarian Indus Valley civilization (Wright, 2009) which was a highly professional civilization from $5000 \mathrm{BCE}$ to $1900 \mathrm{BCE}$. One of the cities was Mohenjo-Daro. Mohenjo-Daro was an elaborately constructed city with streets laid out evenly at right angles and a sophisticated drainage system. The Great Bath, a central structure at the site, was heated and seems to have been a focal point for the community. The citizens were skilled in the use of metals such as copper, bronze, lead, and tin as evidenced by artworks such as the bronze statue of the Dancing Girl and by individual seals. The seals were made of terracotta and were used by merchants to stamp their goods as the professional approval. The cities did not have large buildings for governments, religions, and military protection. They were ruled apparently by low-profile peaceful professionals. The Indus Valley civilization is basically a professional eusocial civilization based on division of professional.

Liberty was established by Athens around 460BCE. Athens established the 
constitution which is called a democracy because it respects the interests not of the minority but of the whole group of citizens. When it was a question of settling private disputes, every citizen was equal before the law. The Roman Republic (509-27 BCE) combined both tyranny and democracy. The Republic was divided into the three basic parts including elected non-hereditary magistrates, a Senate to advise and consent, and popular assemblies. Instead of a king, and to guard against despotism, the Republic chose two consuls as executive magistrates appointed by the popular assembly. The two consuls represented tyranny. The Senate served as an advisory body to the consuls. Throughout most of its existence, the Roman Senate remained the domain of the wealthy. It was the embodiment of oligarchy, a lawmaking body governed by the aristocracy. The democratic part of Roman government was in the form of assemblies, in which the Roman people directly elected executive magistrates. The Roman Republic served as a direct model of government for the writers of the American constitution.

About two thousand years ago, the Roman Empire based on liberal-individualism and the Han Dynasty based on professional-collectivism coexisted as the two long-lasting super powers at about the same time without much interaction. The fall of the Western Roman Empire in 476 CE returned the West Europe back to the feudal nation stage from the mega nation stage, resulting in the loss of liberal individualism. During the 18th century, the Age of Enlightenment centered on reason as the primary source of knowledge dominated the world of ideas in Europe, resulting in the return of liberal individualism and liberal capitalism. During the mega nation stage, there were class conflict between capitalists and proletariats in liberal capitalism and between professional officers and proletariats in professional meritocracy. Karl Marx (1818-1883) lived in this period. During this time, newly industrialized overcrowded cities were expanding, and much of the working class lived in great poverty. Marx saw history as the story of class struggles, in which the oppressed fight against their oppressors. According to Marx, as history unfolded, the victory of one class would pave the way for the future freedom of the rest of society. Marx became a revolutionary German economist and philosopher, and the founder of the Communist movement.

During the split mega nation stage, the highly centralized mega empires in the individualistic West required highly centralized and exclusive monotheism including Zoroastrianism, Christianity, and Islam. After the defeat of Israel and Judah by the mega empires, the failure of polytheism as the alliance of deities for the alliance of nations led the patriotic Israelite prophets to transform polytheism into monotheism (Yahweh) as the mega universal deity to rescue Israel and Judah from the mega empires (Nikiprowetzky, 1975). Mark S. Smith shows how polytheism was a feature of Israelite religion until the seventh and sixth centuries after the defeat of Israel and Judah by the mega empires (Smith, 2001). Highly centralized mega empires in the collective East required highly centralized and 
inclusive Henotheism (theism of one god) to worship a single god without denying the existence or possible existence of other deities.

\subsection{The Split Individualistic-Collectivistic Democracy Stage by the Industrial Revolution}

The Industrial Revolution contains four stages. The first industrial revolution began in Britain in the late $18^{\text {th }}$ century. It was centered on textiles, steam power, and iron. The second industrial revolution was between 1870 and 1914 after the civil war in America. It was centered on steel, railroads, petroleum, chemicals, and electricity. The third industrial revolution as the information revolution began in the 1980s with the proliferation of digital computers, digital record, personal computers, the internet, and information and communications technology. The fourth industrial revolution builds on the third industrial revolution, and combines robotics, artificial intelligence, nanotechnology, quantum computing, biotechnology, the Internet of Things (IoT), decentralized consensus, 3D printing, and autonomous vehicles (Schwab, 2017). The fourth industrial revolution allows highly individualized global production-distribution-information.

The Industrial Revolution brings about affluence and education to all people including poor people, women, and minorities who had little wealth and education before the Industrial Revolution. In the Industrial Revolution, the dramatic increase in productivity lifted most people from the poverty. The Industrial Revolution allows and requires all individuals to be educated. As a result, all people with affluence and education demand the participation in government. The Industrial Revolution transforms mega nations into global democracy where power belongs to all people. The Industrial Revolution transforms meritocracy and capitalism into common professional democracy (collectivism, rule of relation, division of profession, and affluence) and individual liberal democracy (individualism, rule of law, liberty, and affluence), respectively, for all people. At the same time with globalization, meritocracy can be transformed into individual liberal democracy, elite capitalism can be transformed into common professional democracy, common professional democracy can be transformed into individual liberal democracy, and individual liberal democracy can be transformed into common professional democracy. In Marxism, common professional democracy is communism without class conflict. The world now is split into the individual liberal democracy bloc and the common professional democracy bloc.

For the industrialized countries, adventurous production type (strength in invention, productivity, efficiency, and marketing) based on liberal individualism relation is adaptable to individual liberal democracy for individual liberty, while consolidative production type (strength in development, supply chain, economy of scale, and ration) based on professional collectivism relation is adaptable to common professional democracy for common wellbeing.

For more than hundred years, the West has practiced dual individual liberal democracy consisting of individual liberal democracy core and common profes- 
sional democracy complement. The instability in chaotic competitive election in individual liberal democracy can be minimized by meritocratic professional civil service as in common professional democracy. The first European power to implement a successful meritocratic civil service was the British Empire, in their administration of India: "company managers hired and promoted employees based on competitive examinations in order to prevent corruption and favoritism.” (Kazin, Edwards, \& Rothman, 2010). In 1883, the system of appointments to the United States Federal Bureaucracy was revamped by the Pendleton Civil Service Reform Act, partially based on the British meritocratic civil service that had been established years earlier. The act stipulated that government jobs should be awarded on the basis of merit, through competitive exams, rather than ties to politicians or political affiliation.

In the special Marxism by Karl Marx, the final mode is cooperative classless communism, but Marx did not provide much guidance for how a cooperative society would operate without property, class, and state. In reality, the Soviet Union under Lenin and Stalin practiced common professional democracy based on professional collectivism ruled by cooperative professionals for all people without class conflict. The economy was the professionally planned cooperative economy based on consolidative production type consisting of development, supply chain, scale of economy, and ration. The Soviet Union had a well-developed system of professionals based on division of professional in the Soviet Union and the Eastern Europe. The Soviet Union developed the strong consolidative production type for development, supply chain, economy of scale, and ration. By the 1950s, consolidative production type allowed the Soviet Union to rapidly evolve from a mainly agrarian society into a major industrial power (Davies, 1998). The economy continued to grow afterward partially due to the skyrocketed world price of oil in the 1970s benefiting the oil-rich USSR. In terms of GDP, the Soviet Union maintained itself as the second largest economy for much of the Cold War until 1988. However, the Soviet Union neglected to develop adventurous production type as the complementary production type for invention, productivity, efficiency, and marketing until it was too late. Consequently, during the new information revolution in 1980's, the Soviet Union lost the competition against individual liberal democracy with adventurous production type, resulting in the breakup of the Communist bloc in Europe in 1989 and the collapse of the USSR in 1991. The breakup broke the well-developed consolidative production type, moving the economy backward, and the former European communist countries did not recover until recently.

Since the opening and reform in 1978 (Vogel, 2011), China who basically followed the Soviet Union has added adventurous production type as the complement to consolidative production type as the core, and has added individual liberal democracy on the local level as the complement as described by Daniel A. Bell (Bell, 2015). Consequently, according to the World Bank, more than 850 million Chinese people have been lifted out of extreme poverty; China's poverty 
rate fell from 88 percent in 1981 to 0.7 percent in 2015 (The World Bank Group, 2018). In China now, the private sector accounts for more than two-thirds of the economy and 90 percent of Chinese exports ( 43 percent of which are from foreign-owned firms) (Shan, 2019). Therefore, any robust democracy and production type have to have both the cores and the complements.

In the East, Japan with the third largest economy in the world is basically collectivistic under the strong influence of Confucianism. It has collective capitalism (Hundt \& Uttam, 2017) which has been the main policy since WWII. The state has shaped economic institutions in order to achieve specific developmental goals. Industrial policy has been the primary means of state intervention. Japan's collective capitalism relies on cooperation instead of competition as in individualistic capitalism in the West. For examples, a large manufacture company and its suppliers own each other's stocks to form interlocking manufacturer and suppliers. Many companies form such interlocking groups based on cooperation. It is difficult for the individualistic Western companies to penetrate collectivistic Japanese economy. Workers working for large businesses have job security for life, in return for loyalty and hard work based on cooperation. Politically, weak opposition makes Japan look like a one-party system by the Liberal Democratic Party (LDP) (Curtis, 2016), because Japanese do not feel strongly about opposition. The government is dominated by highly professional, powerful, and large bureaucrats (over one million employees). As a result, economically and politically, Japan is collectivistic. As shown in the Hofstede cultural dimension model and in "Varieties of Capitalism in Asia: Critical Studies of the Asia-Pacific" by Hundt and Uttam (Hundt \& Uttam, 2017), most of the South and East Asian countries are collectivistic.

For updating special Marxism, class conflict in the elite governments (individualistic liberal capitalism in the West and collectivistic professional meritocracy in the East) working for few people in the mid-nineteenth century (Marx's time) turned into class mobility in the true democratic governments (individualistic individual liberal democracy in the West and collectivistic common professional democracy as communism in the East) working for all people in the twentieth century (Payne, 1987; Hertel, 2016). Both democracies ultimately have the same lasting core value of serving all people, avoiding class conflict, and increasing intergenerational class mobility. However, in the twenty-first century, the decreasing class mobility in the West becomes troublesome as pointed out by Thomas Piketty in "Capital in the Twenty-First Century" (Piketty, 2013).

Democracy for all people allows religious pluralism. Atheism rejects any theism. Modern religions, including progressive and conservative modern religions, accept both religious pluralism and religions homogeneity. Progressive modern religion accepts religious pluralism more than conservative modern religion. Fundamental religions reject religious pluralism entirely. Extreme religions violently reject religious pluralism. Individualistic religious pluralism promotes individual liberty of religions, while collectivistic religious pluralism promotes co- 
operation among religions. Billy Graham, the most respected Christian evangelist in the world, said, "I used to play God but I can't do that anymore. I used to believe that pagans in far-off countries were lost and were going to hell-if they did not have the Gospel of Jesus Christ preached to them. I no longer believe that," he said carefully. "I believe that there are other ways of recognizing the existence of God-through nature, for instance-and plenty of other opportunities, therefore, of saying 'yes' to God." (Beam, 1978).

\subsection{The Interdependent Eusocial Democracy Stage by the Intelligence Revolution}

Toward the end of the twentieth century after the end of the Cold War and the collapse of the Soviet Union in 1991, the world felt only liberal democracy and free market economy would start the twenty-first century and all future centuries as claimed by political scientist Francis Fukuyama in "The End of History" (Fukuyama, 1992). According to Francis Fukuyama, individual liberal democracy for individual liberty would prevail over common professional democracy for common wellbeing, and individualistic free market economy would overmatch collective planned economy. The twenty-first century turns out to be quite eventful for liberal democracy and free market economy. Individual liberal democracy for individual liberty faced the terrorism crisis in the first year 2001 of the twenty-first century and the subsequent long destructive war in the Middle East. Individualistic market economy faced the disastrous financial crisis in 2008. How did individual liberal democracy and individualistic market economy response to such crises?

The Patriot Act was passed by the U.S. Congress with bipartisan support (357-66 vote in the House and 98-1 vote in the Senate) and signed into law by President George W. Bush on October 26, 2001, just weeks after the September 11 terrorist attacks against the United States (Etzioni, 2004). The Patriot Act allows law enforcement to use surveillance and wiretapping to investigate terror-related crimes. A major player in the Patriot Act was the National Security Agency (NSA) which gathered mass digital phone data from phone companies with permission from a federal court. The NSA became the professional arm of the Patriot Act to do digital surveillance and analysis to supplement people's surveillance and analysis which were often unprofessional and intrusive. Such digital surveillance and analysis allowed the Patriot Act to detect and break terrorists' networks and acts quietly, precisely, efficiently, and professionally. In 2004 testimony before the United States Senate Committee on the Judiciary, FBI Director Robert Mueller said, "the Patriot Act has proved extraordinarily beneficial in the war on terrorism and has changed the way the FBI does business. Many of our counterterrorism successes, in fact, are the direct results of provisions included in the Act." Consequently, the Patriot Act turned individual liberal democracy for individual liberty into common professional democracy for common wellbeing. A systemic weakness of individual liberal democracy is the 
social chaos caused by terrorists. Individual liberal democracy depends on common professional democracy to stop terrorism. In this way, liberty is protected under the safety by common professional democracy. The Patriot Act demonstrates politically the interdependence between individual liberal democracy for individual liberty and common professional democracy for common wellbeing.

The American Recovery and Reinvestment Act (ARRA) as a stimulus package was passed by the Congress and signed into law by President Barack Obama in February 2009 in response to the disastrous financial crisis in 2008. It was a necessary follow-up to President George W. Bush's 2008 plan as the Troubled Asset Recovery Program (TARP) ended the 2008 financial crisis by bailing out large banks. The objectives of the ARRA were to save existing jobs, create new ones, provide temporary relief programs for those most affected by the recession, and invest in infrastructure, education, health, and renewable energy. The TARP and the ARRA basically transformed individualistic free market economy into collective planned economy. The financial crisis from the excessive financial speculation was predicted by Karl Marx in the mid-nineteenth century (Panitch, 2009). Financial crisis from excessive speculation is a systemic weakness of free market economy. Free market economy depends on collective planned economy to rescue it from financial crisis. In February 2009, the cover of Newsweek announced, "WE ARE ALL SOCIALISTS NOW.” (Meacham, 2009) Canada's Financial Post also proclaimed, "Bailout Marks Karl Marx’s Comeback." (Masse, 2008) Free market economy is protected under the collective economic effort from collective planned economy. The TARP and the ARRA demonstrates economically the interdependence between individualistic free market economy and collective planned economy.

Meanwhile, the extensive trade and investment between the West represented by the European Union and North America and the East represented by the East and South Asian countries started from 1960's, and have accelerated in the twenty-first century since China became a member of the World Trade Organization. The West was much more advanced in industry than the East, and had both adventurous production type and consolidative production type. The West, particularly America has outsourced the low-profit consolidative production type (development, supply chain, economy of scale, and ration) to the East, and kept the high-profit adventurous production type (invention, productivity, efficiency, and marketing) in the West. The West imports the consolidative production products which require low-profit development, supply chain, economy of scale, and ration from the East. The East imports the high-profit adventurous production products and services which require invention, productivity, efficiency, and marketing from the West. Essentially, The West imports low-profit mature medium-low-technology, out-sourcing, and contract manufacturing products from the East, and the East imports high-profit new high-technology products and services from the West. Both sides have grown economically from 
the trade and investment.

After about sixty years of such extensive globalization, the West becomes very strong in adventurous production type and deficient in consolidative production type, while the East becomes very strong in consolidative production type and deficient in adventurous production type. The individualistic West depends on the collectivistic East for the products from low-profit development, supply chain, economy of scale, and ration, while the East depends on the West for the products from high-profit invention, productivity, efficiency, and marketing. The result is the interdependent individualism-collectivism. For examples, during the Covid-19 crisis, the West has to rely on the East with development, supply chain, economy of scale, and ration to mass produce the products for medical protection equipment. At the same time, the East has to rely on the West for the products and services in the most advanced technology. Adventurous production type in the West and consolidative production type in the East are interdependent.

The education in the East aims for consolidative production type in terms of gathering and applying knowledge instead of inventing knowledge. For examples, to test gathering and applying knowledge, the Program for International Student Assessment (PISA) is an international assessment that measures 15-year-old students' reading, mathematics, and science literacy every three years. In PISA 2018 (OECD, 2019), children from the East Asian countries ranked high in all three subjects. The top five in Mathematics are China, Singapore, Macau, Hong Kong China, and Chinese Taipei. For the university education as shown in Best Global Universities Rankings by U.S. News \& World Report (U.S. News \& World Report, 2019), America has many top 10 universities in science, while China has many top 10 universities in engineering. The education in the West aims for adventurous production type, while the education in the East aims for consolidative production type.

At the same time, the fourth industrial revolution has accelerated in the twenty-first century. The fourth industrial revolution builds on the third industrial revolution, and combines robotics, artificial intelligence, nanotechnology, quantum computing, biotechnology, the Internet of Things (IoT), decentralized consensus, 3D printing, and autonomous vehicles. The fourth industrial revolution allows highly individualized global production-distribution-information. Different from the previous industrial revolution, the fourth industrial revolution can be called the Intelligence Revolution (Makridakis, 2017). The world now is undergoing the Intelligence Revolution with artificial intelligence, big data, automation, enormous data collection, and digital connection everywhere. Artificial intelligence (AI) is defined as the ability for computers to perceive, learn, reason, and assist in decision-making to solve problems in ways that are similar to humans. AI can be deployed across a range of business functions to take over manual, repetitive and time-consuming tasks undertaken by employees. It can also provide insight into data. The Intelligence Revolution brings extensive 
changes that will also affect all aspects of our society and life. In addition, its impact on firms and employment will be considerable, which results in richly interconnected organizations with decision making based on the analysis and exploitation of "big" data and intensified global competition among firms. People will be capable of buying goods and obtaining services from anywhere in the world using the Internet, and exploiting the unlimited, additional benefits that will open through the widespread usage of AI inventions.

The Intelligence Revolution started in the West. The East has made considerable progress in AI as described by Kai-Fu Lee in "AI Superpowers: China, Silicon Valley, and the New World Order" (Lee, 2018). Lee describes how China is rapidly moving forward to become a global leader in AI. In 2019, Daniel Castro, Michael McLaughlin, and Eline Chivot (Castro, McLaughlin, \& Chivot, 2019) compares China, the European Union, and the United States in terms of their relative standing in the AI economy by examining six categories of metrics-talent, research, development, adoption, data, and hardware. Overall, the United States currently leads in AI, with China rapidly catching up, and the European Union behind both. The United States leads in four of the six categories of metrics (talent, research, development, and hardware), China leads in two (adoption and data), and the European Union leads in none-although it is closely behind the United States in talent. Out of 100 total available points in this report's scoring methodology, the United States leads with 44.2 points, followed by China with 32.3 and the European Union with 23.5. Nonetheless, in the future, when controlling for the size of the labor force in the three regions, the current U.S. lead becomes even larger, while China drops to third place, behind the European Union.

As in other technologies, in AI, the West is strong in adventurous production type, and the East is strong in consolidative production type including adoption and data. Because $\mathrm{AI}$ is still in the stage of invention, the West is strong in talent, research, development, and hardware which constitute the core technology of AI. The East certainly depends on the West for the products and services from invention, productivity, efficiency, and marketing. The West depends on the East for the products from development, supply chain, economy of scale, and ration. For AI, it means that no matter where core AI technological processes are being performed in the West, the AI products are being physically fabricated in the East (Domashneva, 2020). The East makes a very good use of adoption and data in terms of consolidative production types to make life convenient and safe, even though the core technologies belong to the West. Consequently, in the Intelligence Revolution, the West and the East are interdependent. In fact, the interdependent coexistence of adventurous production type and consolidative production type already exists in "Chimerica" to describe the symbiotic relationship between China and the United States according to Niall Ferguson (Ferguson, 2008).

Mentally, under individual liberty, people are happy due to liberty, but they are prone to chaos and fragile mentality without close relations with others 
(Grossmann \& Kross, 2010). Under professional collectivism, people are serious due to professionalism and restriction, but they are stable and durable by close relations with others. Moderate liberty is independence and happiness, but excessive liberty without professionalism (expertise) is chaos as pointed out by Thomas M. Nichols in "The Death of Expertise: The Campaign against Established Knowledge and Why it Matters" (Nichols, 2017). Moderate professionalism is convenience and safety, but excessive professionalism is restriction. Liberal individualism and professional collectivism help each other to moderate liberty and professionalism. Mentally, liberal individualism and professional collectivism are interdependent. Based on theory of mind, people in liberal individualism and professional collectivism have to recognize, respect, and understand each other's mind and each other's baseline.

Politically in crisis, people under liberal individualism can detect widespread crisis faster due to individual initiative, but they are slower in stopping the widespread crisis due to the insufficient collective effort, while people under professional collectivism may detect widespread crisis slower due to the insufficient individual initiative, but they are faster in stopping widespread crisis due to collective effort. The East under professional collectivism managed to overcome the financial crisis in 2008 better than in the West under liberal individualism. It is important for liberal individualism and professional collectivism to work together during crisis. People should use different approaches in the different stages. In the early stage of production and widespread crisis, the approach of liberal individualism takes the lead in the breakthrough invention in production and detection in widespread crisis. In the late stage of production and widespread crisis, the approach of professional collectivism takes the lead in development, supply chain, economy of scale, and ration and in the overcoming of crisis. The 2010s were the hottest decade on record (Wu, 2020). Global warming crisis was first detected by liberal individualism, and can be overcome by professional collectivism. In the past, widespread recession crises were overcome by professional collectivism, and in the future, such widespread recession crises will be overcome by professional collectivism. In crisis, liberal individualism and professional collectivism are interdependent.

The Intelligence Revolution leads to new economic surplus which increases the political size from the split East-West to the interconnected world. Now in the world, all people are interconnected. Crisis in one area can be easily spread to other area. In other words, the world is facing continuous crises, some small and some large. Human society needs artificial intelligence to detect and to overcome such continuous crises. The global warming crisis and the Covid-19 crisis accelerate the transition to the intelligence age from the industrial age. It is similar to the acceleration of the transition from the Bronze Age to the Iron Age in 1177 BEC due to the drought-unrest crisis (Cline, 2014).

The stable whole world contains the interdependent individualism-collectivism. Politically, the interdependence joins individual liberal democracy and common professional democracy into one eusocial democracy based on interdependent 
division of labor between individual liberal democracy and common professional democracy. Interdependent division of labor is the base of eusociality. Eusocial democracy establishes the bases for rule of relation, rule of law, liberty for debates and votes, and professional organizations to deal with various issues. Rule of relation is based on the international community of common destiny as expressed by Chinese government (Zhang, 2018). The common destiny provides the base for international cooperation. Rule of law for the rights to life, liberty, and equality for individuals is based on the Universal Declaration of Human Rights by the United Nations written mostly by American government (Roosevelt et al., 2001). The United Nations provides the liberty for debates and votes and the professional organizations to deal with various issues professionally. Under the international rules and organizations, different nations can govern themselves under different civilizations independently to avoid civilizational conflict.

The establishment of the religious-geographic boundaries ended the religious war in the Thirty Years' War among Protestant and Catholic states. In the same way, the establishment of the cultural-geographic boundaries will end the civilizational clash among civilizational types. As mentioned previously (Chung, 2020), one solution to the civilizational clash is the establishment of twelve international regional defense communities in the "International Regional Defense Community Organization" (the IRDCO) based on rule of boundary from the "Monroe Doctrine" to prevent the outside military intervention from hegemons. Every country in the world belongs to an international regional defense community. The common identities of a regional community include some or all of the shared geography region, shared existing regional international organization, shared dominant cultural-religion, shard dominant language, and shared dominant worldview. Each regional community has at least one economically strong country for its protection and strength. With the regional protective boundary, each regional community enforces the "Monroe Doctrine" that forbids military intrusion from the countries outside of a regional community except the intervention approved by the United Nations. As a result, all overseas military bases as the military intrusion from the countries outside of a regional community have to be abolished. All defense treaties connected to the countries outside of a regional community also have to be ended. The regional communities which are for military defense allow individual nations to maintain all international economic treaties inside and outside of the communities. Different regional communities will have different degrees of economic cooperation within the communities. The International Regional Defense Community Organization provides the permanent world peace and stability.

The interdependence between adventurous production type in the West and consolidative production type in the East based on interdependent division of labor requires rules. The most important rule is free trade between adventurous production type in the West and consolidative production type in the East. Sanction and decoupling hurt both sides in this highly interlocking interdepen- 
dence, and bring down the world economy. With free trade, it is possible to find a fair division of labor between the West and the East to mutual benefit. It is also possible to help each other diversify to mutual benefit. Sanction and decoupling hurt the world economy which people cannot afford during the global crises.

In the twenty-first century, individualism from the West and collectivism from the East are interdependent. The interdependent individualism-collectivism brings about the interdependences between individual liberal democracy and common professional democracy, between free market economy and collective planned economy, between liberty and professionalism, and between adventurous production type and consolidative production type. Individual liberal democracy and common professional democracy become one eusocial democracy based on interdependent division of labor as in eusociality. The production evolution is described in Table 8 and Figure 2. The individualism-collectivism duality is described in Table 9 and Figure 3.

Table 8. The production evolution.

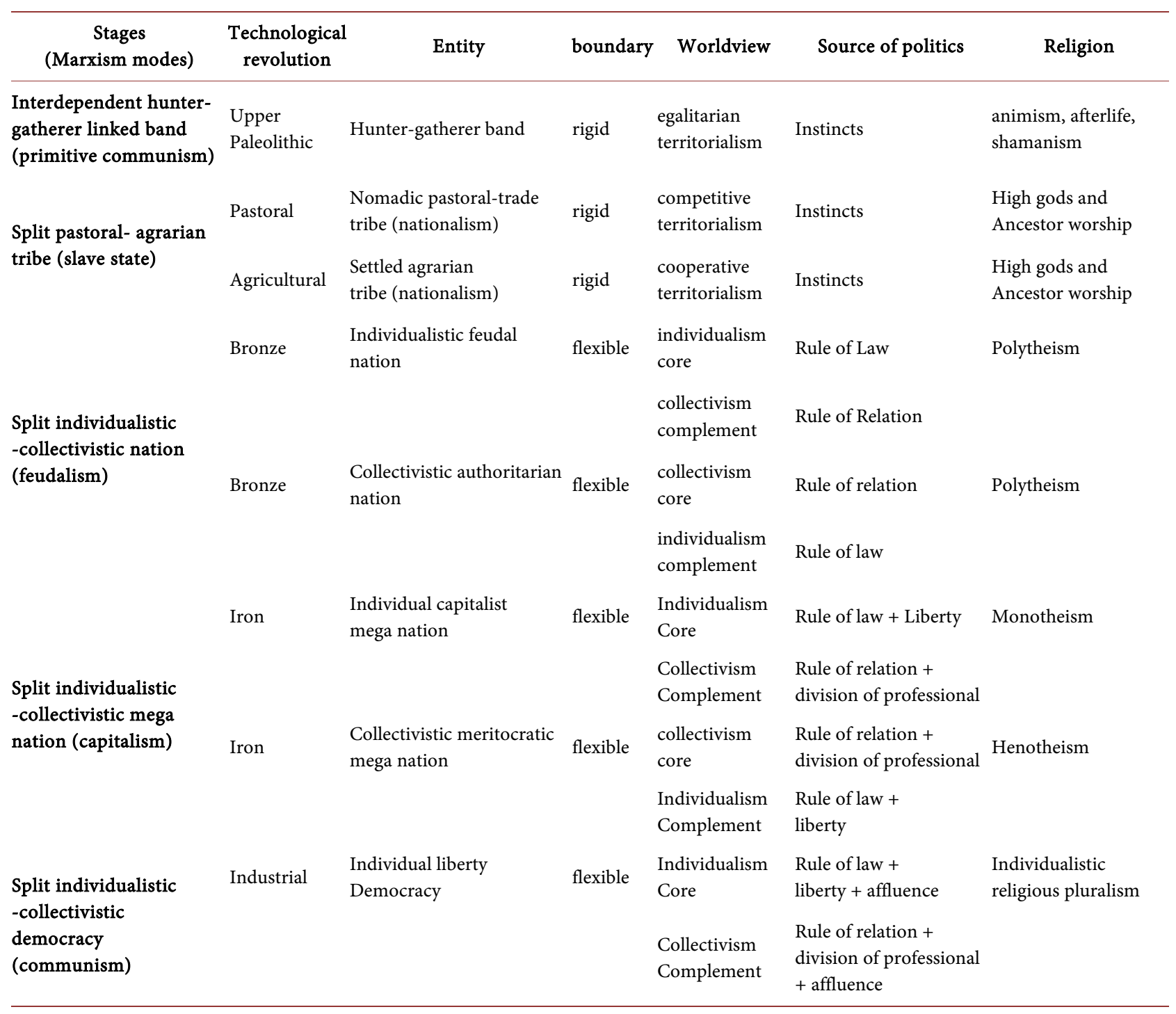




\begin{tabular}{|c|c|c|c|c|c|c|}
\hline & Industrial & $\begin{array}{l}\text { Common wellbeing } \\
\text { Democracy }\end{array}$ & flexible & $\begin{array}{l}\text { Collectivistic } \\
\text { Core }\end{array}$ & $\begin{array}{l}\text { Rule of relation }+ \\
\text { division of professional } \\
+ \text { affluence }\end{array}$ & $\begin{array}{l}\text { Collectivistic religious } \\
\text { pluralism }\end{array}$ \\
\hline \multirow{3}{*}{$\begin{array}{l}\text { Interdependent eusocial } \\
\text { democracy }\end{array}$} & & & & $\begin{array}{l}\text { Individualism } \\
\text { Complement }\end{array}$ & $\begin{array}{l}\text { Rule of law }+ \\
\text { liberty }+ \text { affluence }\end{array}$ & \multirow{3}{*}{$\begin{array}{l}\text { Coexistent } \\
\text { individualistic } \\
\text {-collectivistic } \\
\text { religious pluralism }\end{array}$} \\
\hline & Intelligence & $\begin{array}{l}\text { Interdependent interna- } \\
\text { tionalized } \\
\text { democracy }\end{array}$ & flexible & $\begin{array}{l}\text { Individualism } \\
\text { Collectivistic } \\
\text { Core }\end{array}$ & $\begin{array}{l}\text { National common } \\
\text { wellbeing or individual } \\
\text { liberty democracy }\end{array}$ & \\
\hline & & & & $\begin{array}{l}\text { Individualism } \\
\text { Collectivism } \\
\text { Complement }\end{array}$ & $\begin{array}{l}\text { International liberty }+ \\
\text { division of professional } \\
+ \text { rule of law }+ \text { rule of } \\
\text { relation }\end{array}$ & \\
\hline
\end{tabular}

Table 9. The interdependent individualism-collectivism duality.

\begin{tabular}{ccccccccccc}
\hline Worldview & Yin-yang & Ape & Band & Tribe & civilization & Production Type & Democracy & Economy & Crisis \\
\hline Individualism & yang & chimpanze & hunter & Pastoral & West & Adventurous & $\begin{array}{c}\text { individual } \\
\text { liberal }\end{array}$ & free market & detection \\
Collectivism & yin & bonobo & gatherer & Agrarian & East & consolidative & $\begin{array}{c}\text { common } \\
\text { professional }\end{array}$ & $\begin{array}{c}\text { collective } \\
\text { planned }\end{array}$ & overcoming \\
\hline
\end{tabular}

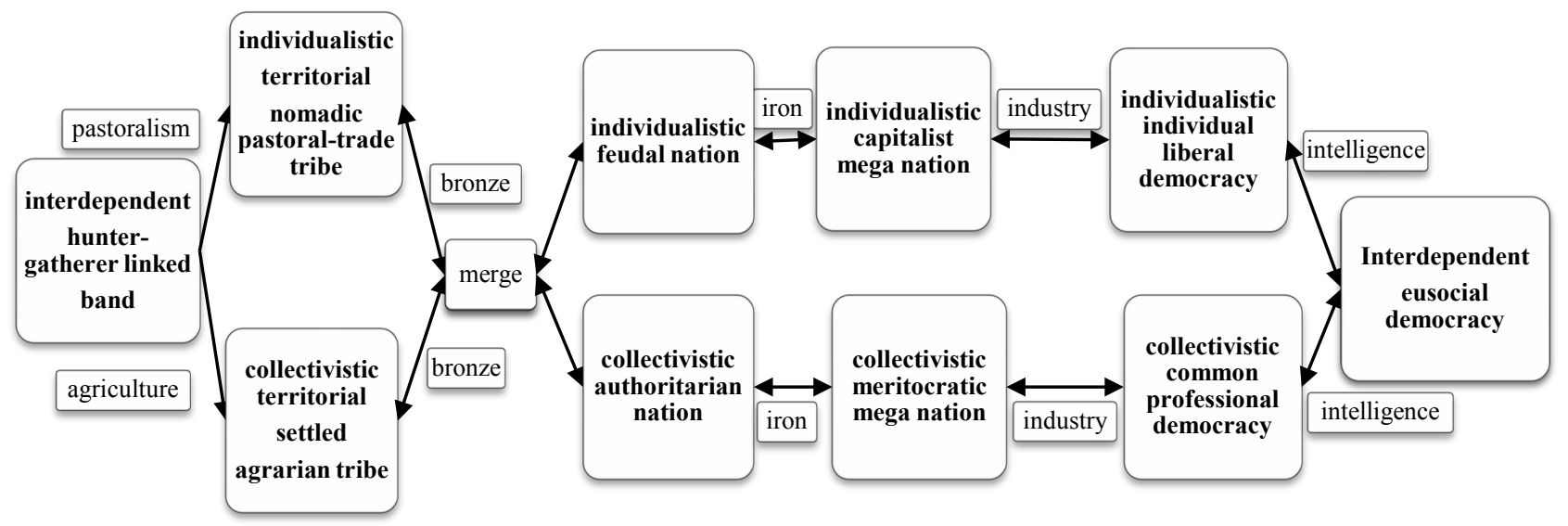

Figure 2. The production evolution.

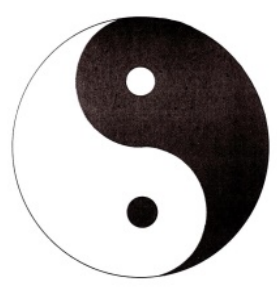

Figure 3. The yin-yang symbol for the individualism-collectivism duality.

\subsection{Special Marxism and General Marxism}

The core of both special Marxism and general Marxism is production. Special 
Marxism is broadened and updated by the $5 \mathrm{~W} 1 \mathrm{H}$ production analysis for all aspect of production and the individualism-collectivism duality for the individualistic Western civilization originated from the Middle East and Greece and the collectivistic Eastern civilization originated from India and China. The 5W1H production analysis consists of when (stages), what (types), how much (energies), why (purposes), who (people), and where (places) to produce. In the production analysis of special Marxism, the modes (stages) of production are the combinations of production forces and production relations. In the production analysis of general Marxism, the modes (stages) in the production evolution are the combinations of the three production forces (exploratory-consolidative types, driver-amiable energies, and ant-grasshopper purposes) and their production relations among production people and places in the production dimension model based on the Hofstede cultural dimension model. In the statistical analysis, the indexes in the production dimension model derived from the indexes in the Hofstede model correlate well with the observed Democracy Index (R2 = $0.4)$ and the GDP Growth Rate $(\mathrm{R} 2=0.8)$. General Marxism is broader than special Marxism in production analysis.

Special Marxism is basically derived from the individualistic Western civilization. General Marxism involves both the individualistic Western civilization and the collectivistic Eastern civilization, so there are two different production evolutions for the West and the East. In special Marxism, the evolution is driven by class historic dialectic where the evolution is derived by class conflict. In general Marxism, the evolution is driven by technological historic dialectic where the evolution is driven by the breakthrough technology from technological revolution, and class conflict is the result of technological historic dialectic. The results from special Marxism and general Marxism are the same. The first five modes (stages) are the linked band stage by the Upper Paleolithic Revolution, the split tribe stage (collective-individualistic territorial tribalism) by the Agricultural-Pastoral Revolution, the split nation stage (authoritarianism-feudalism) by the Bronze Revolution, the split mega nation stage (meritocracy-capitalism) by the Iron Revolution, and the split democracy stage (individual liberal democracy-common professional democracy) by the Industrial Revolution corresponding to the primitive communism, slave state, feudalism, capitalism, and communism modes, respectively in special Marxism.

For updating special Marxism, class conflict in the elite governments (individualistic liberal capitalism in the West and collectivistic professional meritocracy in the East) working for few people in the mid-nineteenth century (Marx's time) turned into class opportunity in the true democratic governments (individualistic individual liberal democracy in the West and collectivistic common professional democracy as communism in the East) working for all people in the twentieth century. Furthermore in updating in the twenty-first century, through increasing globalization in trade and investment, the individualistic West depends on the collectivistic East for the products from low-profit development, supply 
chain, economy of scale, and ration, while the East depends on the West for the products from high-profit invention, productivity, efficiency, and marketing. The result is the interdependent individualism-collectivism. In general Marxism, individualistic individual liberal democracy and collectivistic common professional democracy become one eusocial democracy based on interdependent division of labor as in eusociality. In general Marxism, the production evolution has the interdependent individualism-collectivism at the beginning (hunter-gatherer) and the end (eusocial democracy) and the split individualism-collectivism in between (pastoral-agrarian and West-East).

\section{Summary and Conclusion}

In summary, classical Marxism as special Marxism for the mid-nineteenth century is broadened and updated into general Marxism for the twenty-first century. General Marxism includes the mental origin of production, the $5 \mathrm{~W} 1 \mathrm{H}$ production analysis (when, what, how, why, who, and where to produce) for all aspects of production, human biological evolution, and the individualism-collectivism duality for the individualistic Western civilization originated from the Middle East and Greece and the collectivistic Eastern civilization originated from India and China.

The mental origin of production explains all mental capacities to develop civilized production. The paper proposes that the mental origin of production consists of the social brain for instinctive intragroup relations and worldviews to form the original small human production group, the mental immune system for instinctive mental therapy, theory of imaginary mind for imaginary religious and political entities with their own minds to form cohesive large production group, and the thinking brain for rational rule to form rational civilization.

The $5 \mathrm{~W} 1 \mathrm{H}$ production analysis consists of when (stages), what (types), how much (energies), why (purposes), who (people), and where (places). In the production analysis of special Marxism, the modes (stages) of production are the combinations of production forces and production relations. In the proposed $5 \mathrm{~W} 1 \mathrm{H}$ production analysis of general Marxism, the modes (stages) in the production evolution are the combinations of the three production forces (adventurous-consolidative types, driver-amiable energies, and ant-grasshopper purposes) and their production relations among production people and places in the production dimension model based on the Hofstede cultural dimension model.

The six cultural dimensions in the Hofstede cultural dimension model correspond to six production relations among production people and production places. The Hofstede's six cultural dimensions include individualism versus collectivism (IDV), power distance index (PDI), masculinity versus femininity (MAS), uncertainty avoidance index (UAI), long term orientation versus short term normative orientation (LTO), and indulgence versus restraint (IVR) to represent differences among national cultures, and each dimension in each na- 
tional culture is given a numerical index from survey of people in different nations.

In the production dimension model, the production forces (adventurous-consolidative types, driver-amiable energies, and ant-grasshopper purposes) are derived from the pairs of (IDV-PDI, MAS-UAI, and LTO-IVR, respectively) of cultural dimensions in the Hofstede cultural dimension model. In the statistical analysis, the indexes from the production dimension model derived from the indexes of the Hofstede model correlate well with the observed Democracy Index $(\mathrm{R} 2=0.4)$ and the GDP Growth Rate $(\mathrm{R} 2=0.8)$. Countries can be characterized by the production forces.

In human biological evolution, the hunter-gatherer band was evolved to have the interdependent division of labor between hunters and gathers. The foundation of the interdependent division of labor is theory of mind for hunters and gatherers to recognize, respect, and understand each other's mind in terms of different hunter's mind and gatherer's mind. The production type for hunters is adventurous production type which is high risk and high nutrition (high-profit) to hunt dangerous and unpredictable food targets, while the production type for gatherers is consolidative production type which is low risk and low nutrition (low-profit) to collect safe and predictable food targets. The production evolution starts with interdependent cooperative hunter-gatherer band stage which is the primitive communism mode in Marxism.

The agrarian-pastoral revolution split hunter-gatherer band into nomadic pastoral tribe and settled agrarian tribe. Nomadic pastoralists were dominated by hunter mentality with adventurous production type in high risk-profit and adventurous frequent migration, military plundering, and risky nomadic trade. Settled agriculturalists were dominated by gatherer mentality with consolidative production type in low risk-profit consolidative irrigation and infrastructure. Pastoralists developed individualism, while agriculturalists developed collectivism as shown by Richard E. Nisbett. The split agrarian-pastoral tribe stage corresponds to the slave state mode in special Marxism.

In the Bronze Age, pastoralists with horse-powered wheeled vehicles and chariots invaded agrarian tribes, resulting in the formation of nations consisting of both pastoral and agrarian tribes. The West originated from the Middle East and Greece is dominated by individualism, while the East originated from India and China is dominated by collectivism. In the West, rule of law was added to individualism to form individualistic feudal nations, corresponding to feudalism stage in special Marxism. In the East, rule of relation was added to collectivism to form collectivistic authoritarian nations. The stage is the split feudalism- authoritarian stage.

In the Iron Age, abundant and high-quality iron allowed nations to expand into mega nations, such as mega empires. In the West, liberty was added to rule of law and individualism to form individualistic capitalist mega nations such as the Roman Empire and the capitalist nations in the nineteenth century before 
the highly developed industrialization in Europe. Individualistic capitalist mega nation stage corresponds to capitalism stage in special Marxism. In the East, division of professional was added to rule of relation and collectivism to form collectivistic meritocracy mega nations. The exploitations of capitalists and professional officials over common people constitute the class conflicts in special Marxism in the mid-nineteenth century.

In the twentieth century for the highly developed Industrial Age, affluence from industrialization provides enough wealth and education to transform elite individualistic liberal capitalism and collectivistic professional meritocracy working for few people into individualistic individual liberal democracy (individualism + rule of law + liberty + affluence) and collectivistic common professional democracy (collectivism + rule of relation + division of professional + affluence) working for all people. Common professional democracy is effectively communism. Class conflict in special Marxism in the mid-nineteenth century (Marx's time) was transformed into class mobility in democracy. For the industrialized countries, adventurous production type (strength in invention, productivity, efficiency, and marketing) based on liberal individualism relation is adaptable to individual liberal democracy for individual liberty, while consolidative production type (strength in development, supply chain, economy of scale, and ration) based on professional collectivism relation is adaptable to common professional democracy for common wellbeing.

The first five modes (stages) are the linked band stage by the Upper Paleolithic Revolution, the split tribe stage (collective-individualistic territorial tribalism) by the Agricultural-Pastoral Revolution, the split nation stage (authoritarianism-feudalism) by the Bronze Revolution, the split mega nation stage (meritocracy-capitalism) by the Iron Revolution, and the split democracy stage (individual liberal democracy-common professional democracy) by the Industrial Revolution corresponding to the primitive communism, slave state, feudalism, capitalism, and communism modes, respectively in special Marxism.

In the twenty-first century, during the terrorism crisis and the financial crisis, individualistic individual liberal democracy with free market economy turned into collectivistic common professional democracy with collective planned economy to overcome the crises. As a result, liberal democracy with free market economy and common professional democracy with collective planned economy become interdependent. Through increasing globalization in trade and investment, the individualistic West depends on the collectivistic East for consolidative production type from low-profit development, supply chain, economy of scale, and ration, while the East depends on the West for adventurous production type from high-profit invention, productivity, efficiency, and marketing. As a result, production types become interdependent. The result is the interdependent individualism-collectivism for democratic systems, economic systems, and production types.

At the same time, with additional surplus, the Intelligence Revolution in the 
twenty-first century increases the political size from the split West-East to the interconnected world. The stable interconnected world contains the interdependent individualism-collectivism for eusocial democracy based on interdependent division of labor between individual liberal democracy and common professional democracy. Economically and politically, after the split for more than ten thousand years, hunters (the West) and gatherers (the East) again converge in the form of interdependent division of labor based on theory of mind to recognize, respect, and understanding each other's mind.

In conclusion, the surpluses from the Upper Paleolithic Revolution, the Agricultural-Pastoral Revolution, the Bronze Revolution, the Iron Revolution, the Industrial Revolution, and the Intelligence Revolution increase the political sizes dialectically in the order of band, tribe, nation, mega nation, the split West-East, and the interconnected world, respectively. The core of general Marxism is that eusocial democracy based on the interdependent division of labor between individual liberal democracy and common professional democracy in the stable interconnected world is inevitable through the dialectic view of the production evolution. Only humans can have eusocial democracy, because only humans and no other animals have theory of mind to recognize, respect, and understand each other's mind in interdependent division of labor.

\section{Conflicts of Interest}

The author declares no conflicts of interest regarding the publication of this paper.

\section{References}

American Psychiatric Association (2013). Diagnostic and Statistical Manual of Mental Disorders (5th ed.). Washington DC: American Psychiatric Publishing. https://doi.org/10.1176/appi.books.9780890425596

Angus, D. et al. (2015). Limitations in Social Anticipation Are Independent of Imaginative and Theory of Mind Abilities in Children with Autism but Not in Typically Developing Children. Autism, 19, 604-612. https://doi.org/10.1177/1362361314537911

Anthony, D. (2010). The Horse, the Wheel, and Language: How Bronze-Age Riders from the Eurasian Steppes Shaped the Modern World. Princeton, NJ: Princeton University Press. https://doi.org/10.2307/j.ctt7sjpn

Bar-Yosef, O. (2002). The Upper Paleolithic Revolution. Annual Review of Anthropology, 31, 363-393. https://doi.org/10.1146/annurev.anthro.31.040402.085416

Beam, J. (1978). I Can't Play God Anymore. McCall's Magazine, 154-158.

Bell, D. (2015). The China Model: Political Professionalism and the Limits of Democracy. Princeton, NJ: Princeton University Press. https://doi.org/10.1515/9781400865505

Bloch, M. (2006). Why Religion Is Nothing Special but Is Central. Philosophical Transactions of the Royal Society B, 363, 2055-2061. https://doi.org/10.1098/rstb.2008.0007

Calarge, C., Andreasen, N., \& O’Leary, D. (2003). Visualizing How One Brain Understands Another: A PET Study of Theory of Mind. American Journal of Psychiatry, 160, 1954-1964. https://doi.org/10.1176/appi.ajp.160.11.1954

Carvalho, S. et al. (2012). Chimpanzee Carrying Behaviour and the Origins of Human 
Bipedality. Current Biology, 22, R180-R181. https://doi.org/10.1016/j.cub.2012.01.052

Castro, D., McLaughlin, M., \& Chivot, E. (2019). Who Is Winning the AI Race: China, the EU or the United States? Center for Data Innovation, 19 August 2019.

https://www.datainnovation.org/2019/08/who-is-winning-the-ai-race-china-the-eu-orthe-united-states/

Chan, P. et al. (2016). Theory of Mind Deficit Is Associated with Pretend Play Performance, but Not Playfulness, in Children with Autism Spectrum Disorder. Hong Kong Journal of Occupational Therapy, 28, 43-52. https://doi.org/10.1016/j.hkjot.2016.09.002

Chung, D. (2016). The Basic Principles of Kin Sociality and Eusociality: Human Evolution. Natural Science, 8, 8-19. https://doi.org/10.4236/ns.2016.81002

Chung, D. (2018a). The Mental Protection System for Protective Behaviors: The Social Brain and the Mental Immune System. Journal of Behavioral and Brain Science, 8, 31-55. https://doi.org/10.4236/jbbs.2018.81003

Chung, D. (2018b). The Eight Stages of Psychosocial Protective Development: Developmental Psychology. Journal of Behavioral and Brain Science, 8, 369-398. https://doi.org/10.4236/jbbs.2018.86024

Chung, D. (2018c). Language Neuromechanics: The Human Biological-Language Evolution. Journal of Behavioral and Brain Science, 8, 447-472. https://doi.org/10.4236/jbbs.2018.88028

Chung, D. (2020). The Interdependent Coexistence of the Rational Civilizations: The Mental Origin of Civilizations. Journal of Behavioral and Brain Science, 10, 46-94. https://doi.org/10.4236/jbbs.2020.101004

Cline, E. (2014). 1177 B.C.: The Year Civilization Collapsed. Princeton, NJ: Princeton University Press. https://doi.org/10.1515/9781400849987

Cohen, T., Montoya, R., \& Insko, C. (2006). Group Morality and Intergroup Relations: Cross-Cultural and Experimental Evidence. Personality and Social Psychology Bulletin, 32, 1559-1572. https://doi.org/10.1177/0146167206291673

Cozolino, L. (2006). The Neuroscience of Human Relationships: Attachment and the Developing Social Brain. New York: W. W. Norton \& Co.

Crespi, B. J., \& Douglas, Y. (1995). The Definition of Eusociality. Behavior Ecology, 6, 109-115. https://doi.org/10.1093/beheco/6.1.109

Cunliffe, B. (2001). The Oxford Illustrated History of Prehistoric Europe. Oxford: Oxford University Press.

Curtis, G. (2016). Weak Opposition Makes Japan Look Like a One-Party System. Financial Review, 18 September 2016.

Davies, P. (2010). Urban Religion and Rural Religion. In F. Stavrakopoulou, \& J. Barton (Eds.), Religious Diversity in Ancient Israel and Judah (pp. 103-115). New York: Continuum International Publishing Group.

Davies, R. (1998). Soviet Economic Development from Lenin to Khrushchev. Cambridge, UK: Cambridge University Press. https://doi.org/10.1017/CBO9780511622335

Dixson, A., \& Dixson, B. (2011). Venus Figurines of the European Paleolithic: Symbols of Fertility or Attractiveness? Journal of Anthropology, 2011, Article ID: 569120. https://doi.org/10.1155/2011/569120

Domashneva, H. (2020). The Future of AI Depends on Asia. The Diplomat, 29 February 2020. https://thediplomat.com/2020/02/the-future-of-ai-depends-on-asia/

Dunbar, R. (1993). Coevolution of Neocortex Size, Group Size and Language in Humans. Behavioral and Brain Sciences, 16, 681-694.

https://doi.org/10.1017/S0140525X00032325 
Dunbar, R. (2009). The Social Brain Hypothesis and Its Implications for Social Evolution. Annals of Human Biology, 36, 562-572. https://doi.org/10.1080/03014460902960289

Dunbar, R. (2016). The Social Brain Hypothesis and Human Evolution. Oxford Research Encyclopedia of Psychology. https://doi.org/10.1093/acrefore/9780190236557.013.44

Erikson, E., \& Erikson, J. (1998). The Life Cycle Completed. New York: W. W. Norton \& Company.

Etzioni, A. (2004). How Patriotic Is the Patriot Act?: Freedom Versus Security in the Age of Terrorism. New York, NY: Routledge. https://doi.org/10.4324/9780203997130

Ferguson, N. (2008). Team “Chimerica”. The Washington Post, 17 November 2008.

Fonagy, P., Gergely, G., Jurist, E., \& Target, M. (2002). Affect Regulation, Mentalization and the Development of the Self. New York: Other Press.

Frith, C. (2007). The Social Brain? Philosophical Transactions of the Royal Society B: Biological Sciences, 362, 671-678. https://doi.org/10.1098/rstb.2006.2003

Fukuyama, F. (1992). The End of History and the Last Man. New York: Free Press.

Grossmann, I., \& Kross, E. (2010). The Impact of Culture on Adaptive versus Maladaptive Self-Reflection. Psychological Science, 21, 1150-1157.

http://pss.sagepub.com/content/early/2010/07/12/0956797610376655 https://doi.org/10.1177/0956797610376655

Haakonssen, K. (1996). Natural Law and Moral Philosophy: From Grotius to the Scottish Enlightenment. Cambridge, UK: Cambridge University Press. https://doi.org/10.1017/CBO9781139172905

Hamilton, W. (1964). The Genetical Evolution of Social Behavior II. Journal of Theoretical Biology, 7, 17-52. https://doi.org/10.1016/0022-5193(64)90039-6

Hamlin, J., Mahajan, N., \& Wynn, K. (2013). Not Like Me = Bad: Infants Prefer Those Who Harm Dissimilar Others. Psychological Science, 24, 589-594.

https://doi.org/10.1177/0956797612457785

Hertel, F. (2016). Social Mobility in the 20th Century: Class Mobility and Occupational Change in the United States and Germany. New York: Springer.

Hetzron, R. (1997). The Semitic Languages. London/New York: Routledge.

Heyes, C. (2015). Animal Mindreading: What's the Problem? Psychonomic Bulletin \& Review, 22, 313-327. https://doi.org/10.3758/s13423-014-0704-4

Hofstede, G. et al (2010). Cultures and Organizations: Software of the Mind. London: McGraw-Hill.

Hundt, D., \& Uttam, J. (2017). Varieties of Capitalism in Asia: Critical Studies of the Asia-Pacific. London: Palgrave Macmillan. https://doi.org/10.1057/978-1-349-58974-6

Jiang, G., Lo, T., \& Garris, C. (2012). Formation and Trend of Guanxi Practice and Guanxi Phenomenon. International Journal of Criminology and Sociology, 1, 207-220. https://doi.org/10.6000/1929-4409.2012.01.19

Joas, H., \& Bellah, R. (2012). The Axial Age and Its Consequences. Cambridge, MA: Harvard University Press. https://doi.org/10.4159/harvard.9780674067400

Judis, J. (2014). Marx Is Dead, Long Live Marx’s Ideas. Dissent, 61, 76-80. https://www.dissentmagazine.org/article/marx-is-dead-long-live-marxs-ideas https://doi.org/10.1353/dss.2014.0020

Kapogiannis, D. et al. (2009). Cognitive and Neural Foundations of Religious Belief. Proceedings of the National Academy of Sciences of the United States of America, 106, 4876-4881. https://doi.org/10.1073/pnas.0811717106

Kapogiannis, D. et al. (2014). Brain Networks Shaping Religious Belief. Brain Connectiv- 
ity, 4, 70-79. https://doi.org/10.1089/brain.2013.0172

Kazin, M., Edwards, R., \& Rothman, A. (2010). The Princeton Encyclopedia of American Political History (Vol. 2, p. 142). Princeton, NJ: Princeton University Press. https://doi.org/10.1515/9781400833566

Lee, K. (2018). AI Superpowers: China, Silicon Valley, and the New World Order. Boston, MA: Houghton Mifflin Harcourt.

Lewis-Williams, D. (2002). The Mind in the Cave: Consciousness and the Origins of Art. London, UK: Thames \& Hudson.

Lovejoy, C. (2009). Reexamining Human Origins in Light of Ardipithecus ramidus. Science, 326, 74-74e8. https://doi.org/10.1126/science.1175834

Makridakis, S. (2017). The Forthcoming Artificial Intelligence (AI) Revolution: Its Impact on Society and Firms. Futures, 90, 46-60. https://doi.org/10.1016/j.futures.2017.03.006

Marx, K. (1990). Capital: A Critique of Political Economy (Vol. 1, Trans. Ben Fowkes). New York: Penguin.

Masse, M. (2008). Bailout Marks Karl Marx’s Comeback. Canada Financial Post, 29 September 2008.

McAdams, D., \& De St. Aubin, E. (1992). A Theory of Generativity and Its Assessment through Self-Report, Behavioral Acts, and Narrative Themes in Autobiography. Journal of Personality and Social Psychology, 62, 1003-1015. https://doi.org/10.1037/0022-3514.62.6.1003

McDonald, M., Navarrete, C., \& Van Vugt, M. (2012). Evolution and the Psychology of Intergroup Conflict: The Male Warrior Hypothesis. Philosophical Transactions of the Royal Society B: Biological Sciences, 367, 670-679.

Meacham, J. (2009). We Are All Socialists Now. Newsweek, 6 February 2009.

Merrill, D., \& Reid, R. (1999). Personal Styles and Effective Performance. New York: CRC Press.

Muhly, J. (2003). Metalworking/Mining in the Levant. In S. Richard (Ed.), Near Eastern Archaeology: A Reader (pp. 174-183). Winona Lake, IN: Eisenbrauns.

Nesdale, D., \& Duffy, A. (2011). Social Identity, Peer Group Rejection, and Young Children's Reactive, Displaced, and Proactive Aggression. British Journal of Developmental Psychology, 29, 823-841. https://doi.org/10.1111/j.2044-835X.2010.02012.x

Newar, S. (2016). Dalits of Hinduism: Dharma's Fight for Lost Children. New Delhi, India: Agniveer.

Nichols, T. (2017). The Death of Expertise: The Campaign against Established Knowledge and Why It Matters. New York: Oxford University Press USA.

Nikiprowetzky, V. (1975). Ethical Monotheism. Daedalus, 104, 80-81.

Nisbett, R. (2004). The Geography of Thought: How Asians and Westerners Think Differently...and Why. New York: Free Press.

Nisbett, R. et al. (2001). Culture and Systems of Thought: Holistic versus Analytic Cognition. Psychological Review, 108, 291-310. https://doi.org/10.1037/0033-295X.108.2.291

Norenzayan, A. et al. (2016). The Cultural Evolution of Prosocial Religions. Behavioral And Brain Sciences, 39, e1. https://doi.org/10.1017/S0140525X14001356

Norenzayan, A., Gervais, W., \& Trzesniewski, K. (2012). Mentalizing Deficits Constrain Belief in a Personal God. PLoS ONE, 7, e36880.

https://doi.org/10.1371/journal.pone.0036880

OECD (2019). PISA 2018 Results. 
https://www.oecd.org/pisa/publications/pisa-2018-results.htm

Panitch, L. (2009). Thoroughly Modern Marx. Foreign Policy, 30 September 2009.

Payne, G. (1987). Mobility and Change in Modern Society. London: Palgrave Macmillan. https://doi.org/10.1007/978-1-349-18529-0

Peoples, H., Duda, P., \& Marlowe, F. (2016). Hunter-Gatherers and the Origins of Religion. Human Nature, 27, 261-282. https://doi.org/10.1007/s12110-016-9260-0

Piketty, T. (2013). Capital in the Twenty-First Century (translated by Arthur Goldhammer). Cambridge, MA: Harvard University Press.

Roosevelt, E. et al. (2001). Universal Declaration of Human Rights. Bedford, MD: Applewood Book.

Sahlins, M. (1968). Notes on the Original Affluent Society. In R. Lee, \& I. DeVore (Eds.), Man the Hunter (pp. 85-89). New York: Aldine de Gruyter.

Schwab, K. (2017). The Fourth Industrial Revolution. New York: Crown Publishing Group.

Scott, F., \& Baron-Cohen, S. (1996). Imagining Real and Unreal Objects: Evidence of a Dissociation in Autism. Journal of Cognitive Neuroscience, 8, 400-411. https://doi.org/10.1162/jocn.1996.8.4.371

Shan, W. (2019). The Unwinnable Trade War. Foreign Affairs 98-6.

Shilling, C., \& Mellor, P. (1998). Durkheim, Morality and Modernity: Collective Effervescence, Homo Duplex and the Sources of Moral Action. British Journal of Sociology, 49, 193-209. https://doi.org/10.2307/591309

Shultz, S., \& Dunbar, R. (2007). The Evolution of the Social Brain: Anthropoid Primates Contrast with Other Vertebrates. Proceeding of Royal Society B, 274, 2429-2436. https://doi.org/10.1098/rspb.2007.0693

Shultz, T., Hartshorn, M., \& Kaznatcheev, A. (2009). Why Is Ethnocentrism More Common than Humanitarianism? In N. A. Taatgen, \& H. van Rijn (Eds.), Proceedings of the 31st Annual Conference of the Cognitive Science Society (pp. 2010-2015). Austin, TX: Cognitive Science Society.

Slater, C. L. (2003). Generativity versus Stagnation: An Elaboration of Erikson's Adult Stage of Human Development. Journal of Adult Development, 10, 53-65. https://doi.org/10.1023/A:1020790820868

Smith, M. (2001). Untold Stories: The Bible and Ugaritic Studies in the Twentieth Century. Peabody, MA: Hendrickson Publishers.

Sperber, J. (2013). Karl Marx: A Nineteenth-Century Life. New York: W. W. Norton \& Company.

Steadman, L., Palmer, C., \& Tilley, C. (1996). The Universality of Ancestor Worship. Ethnology, 35, 63-76. https://doi.org/10.2307/3774025

Stern, E. (2001). Archaeology of the Land of the Bible, Volume II. The Assyrian. New York: Doubleday.

Swanson, G. (1960). The Birth of the Gods: The Origin of Primitive Belief. Ann Arbor, MI: University of Michigan Press. https://doi.org/10.3998/mpub.6484

Tan, C., \& Geng, Y. (2005). India and China: Twenty Centuries of Civilization Interaction and Vibrations (p. 128). Ann Arbor, MI: University of Michigan Press.

Taylor, M. (1999). Imaginary Companions and the Children Who Create Them. New York: Oxford University Press.

Taylor, M. et al. (2004). The Characteristics and Correlates of Fantasy in School-Age Children: Imaginary Companions, Impersonation, and Social Understanding. Deve- 
lopmental Psychology, 40, 1173-1187. https://doi.org/10.1037/0012-1649.40.6.1173

The Economist Intelligence Unit (2020). Democracy Index 2019.

https://www.eiu.com/topic/democracy-index

The World Bank Group (2018). China: Systematic Country Diagnostic. http://documents.worldbank.org/curated/en/147231519162198351/pdf/China-SCD-pu blishing-version-final-for-submission-02142018.pdf

Tulogdi, A. et al. (2010). Brain Mechanisms Involved in Predatory Aggression Are Activated in a Laboratory Model of Violent Intra-Specific Aggression. European Journal of Neuroscience, 32, 1744-1753. https://doi.org/10.1111/j.1460-9568.2010.07429.x

Tulogdi, A. et al. (2015). Neural Mechanisms of Predatory Aggression in Rats-Implications for Abnormal Intraspecific Aggression. Behavioural Brain Research, 283, 108-115. https://doi.org/10.1016/j.bbr.2015.01.030

Turner, J. C., \& Reynolds, K. J. (2010). The Story of Social Identity. In T. Postmes, \& N. Branscombe (Eds.), Rediscovering Social Identity: Key Readings (pp. 13-32). New York: Psychology Press.

U.S. News \& World Report (2019). Best Global Universities Rankings. U.S. News \& World Report. https://www.usnews.com/education/best-global-universities/rankings

Ventura, L. (2019). Countries with Highest GDP Growth 2019. Global Finance Magazine, 24 April 2019.

https://www.gfmag.com/global-data/economic-data/countries-highest-gdp-growth

Vogel, E. (2011). Deng Xiaoping and the Transformation of China. Cambridge, MA: The Belknap Press of Harvard University Press. https://doi.org/10.4159/harvard.9780674062832

Westen, D. (2008). The Political Brain: The Role of Emotion in Deciding the Fate of the Nation. New York: Public Affairs.

White, T. D. et al. (2009). Ardipithecus ramidus and the Paleobiology of Early Hominins. Science, 326, 64-86. https://doi.org/10.1126/science.1175802

Wilson, E. O. (2012). The Social Conquest of the Earth. New York: W. W. Norton \& Company.

Wilson, M. et al. (2014). Lethal Aggression in Pan Is Better Explained by Adaptive Strategies than Human Impacts. Nature, 513, 414-417. https://doi.org/10.1038/nature13727

Wrangham, R. (2018). Two Types of Aggression in Human Evolution. Proceedings of the National Academy of Sciences of the United States of America, 115, 245-253. https://doi.org/10.1073/pnas.1713611115

Wright, R. (2009). The Ancient Indus: Urbanism, Economy, and Society. Cambridge, UK: Cambridge University Press.

Wu, K. (2020). The 2010s Were the Hottest Decade on Record. What Happens Next? Smithsonian Magazine, 16 January 2020.

Wunn, I. (2000). Beginning of Religion. Numen, 47, 417-453. https://doi.org/10.1163/156852700511612

Yuki, M. et al. (2005). Cross-Cultural Differences in Relationship- and Group-Based Trust. Personality and Social Psychology Bulletin, 31, 48-62. https://doi.org/10.1177/0146167204271305

Zatrev, J. (2014). The Co-Evolution of Human Intersubjectivity, Morality, and Language. In D. Dor, C. Knight, \& J. Lewis (Eds.), The Social Origins of Language (pp. 249-266). Oxford, UK: Oxford University Press. 
Zhang, D. (2018). The Concept of "Community of Common Destiny" in China's Diplomacy: Meaning, Motives and Implications. Asia \& the Pacific Policy Studies, 5, 196-207. https://doi.org/10.1002/app5.231 